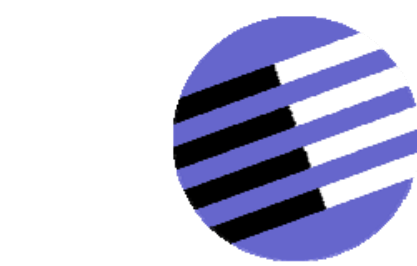

GOVERNANCE AND THE EFFICIENCY

OF ECONOMIC SYSTEMS

GESY

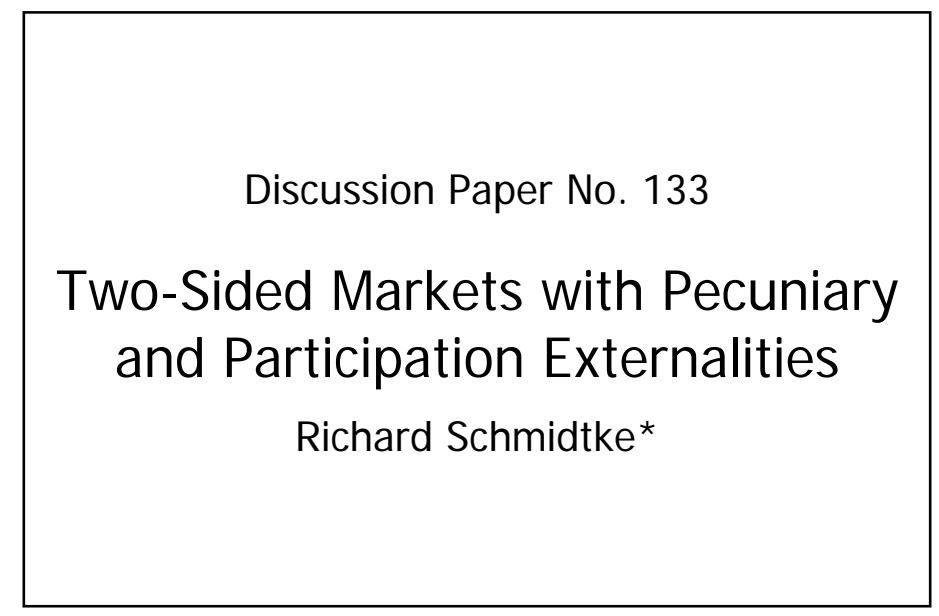

June 2006

*Richard Schmidtke, Department of Economics, University of Munich, Akademiestr. 1/III, 80799 Munich, Germany, Tel: +49-89-2180 3957, Fax: +49-89-2180 2767, Richard.Schmidtke@Irz.uni-muenchen.de

Financial support from the Deutsche Forschungsgemeinschaft through SFB/TR 15 is gratefully acknowledged. 


\title{
Two-Sided Markets with Pecuniary and Participation Externalities*
}

\author{
Richard Schmidtke ${ }^{\dagger}$ \\ University of Munich
}

June 22, 2006

\begin{abstract}
The existing literature on "two-sided markets" addresses participation externalities, but so far it has neglected pecuniary externalities between competing platforms. In this paper we build a model that incorporates both externalities. In our setup differentiated platforms compete in advertising and offer consumers a service free of charge (such as a TV program) that is financed through advertising. We show that advertising can exhibit the properties of a strategic substitute or complement. Surprisingly, there exist cases in which platforms benefit from market entry. Moreover, we show that from a welfare point of view perfect competition is not always desirable.
\end{abstract}

JEL-classification numbers: D43, L13, L82

Keywords: two-sided markets, broadcasting, advertising, market entry, digital television.

\footnotetext{
*I would like to thank Christa Hainz, Monika Schnitzer, Jean Tirole, Markus Reisinger, Thomas A. Weber and participants of the Lunch Seminar at the University of Toulouse, the 2nd CEPR School in Applied Industrial Organization, the Kiel-Munich Workshop, the SFB Transregio IO Summer School and the 3. Media Workshop for helpful comments and suggestions. I am grateful for financial support from the "Kurt Fordan Förderverein". Parts of this paper were written at the University of Toulouse. I am very grateful for the hospitality and the support that I received during my stay. Financial support from the Deutsche Foschungsgemeinschaft through SFB/TR 15 is gratefully acknowledged.

${ }^{\dagger}$ Department of Economics, University of Munich, Akademiestr. 1/III, 80799 Munich, Germany, Tel.: +49-89-2180 3957, Fax.: +49-89-2180 2767, e-mail: Richard.Schmidtke@lrz.uni-muenchen.de
} 


\section{Introduction}

A series of recent papers have looked at competition and regulation in the television and radio broadcasting market by using "two-sided market" models. In these setups platforms, which are broadcasting channels, match viewers and advertisers. Viewers dislike advertisements and competition has the special feature that each platform has a "participation externality" on its competitors. If a platform changes its advertising level, then it influences its own and the competitors' number of viewers. This is an externality that works via the viewer market.

In the real world, however, platforms do not only experience participation externalities, but also pecuniary externalities. In contrast to participation externalities, which work via the viewer market, pecuniary externalities work via the advertising market. Hence, we will take into account that a change in a channel's advertising level does not only affect the distribution of the viewers between the channels, but it also changes the broadcasters' total supply in the advertising market. When the broadcasters' total supply changes, then the market price for advertising has to adjust in order to clear the market. This price adjustment changes the revenue of all platforms and yields a pecuniary externality. So far, this pecuniary externality has been neglected in the existing literature. In this paper we show that pecuniary externalities are important because they influence the theoretical predictions substantially.

In the following we illustrate the existence of pecuniary externalities with two examples. In Germany, free available public broadcasting channels are competing with free available private broadcasting channels. The public broadcasting channels are financed through fees and are not allowed to offer advertising after 8 $\mathrm{pm}$. The private channels are allowed to offer advertising after $8 \mathrm{pm}$. The public broadcasting channels are currently running a deficit. Hence, there is a debate in Germany: Should one increase the fee or should one allow the public broadcasting channels to offer advertising after $8 \mathrm{pm}$ in order to balance their budget? The position of the private channels is: Do not allow them to offer advertisements after $8 \mathrm{pm}$. Instead, increase the fee or force them to reduce their expenditures! ${ }^{1}$ This statement is surprising. Given our existing knowledge of competition in such a

\footnotetext{
${ }^{1}$ Press release "Verband Privater Rundfunkt und Telekommunikation (VPRT), 26.9.2003"
} 
two-sided market, advertising after 8 pm decreases the attractiveness of the public channels. The resulting participation externality should be in the interest of the private channels. Therefore, private channels should like the idea of advertising on public channels. However, the neglected aspect here is that private channels fear that the additional time for commercials decreases the price for advertisements. Due to this pecuniary externality, they dislike the idea of advertisements on public channels.

The other example is taken from the US television market. In the 70s the Department of Justice (DOJ) alleged that the "Code of Conduct" of the National Association of Broadcasters (NAB), which regulated the competition between the broadcasting channels, violated antitrust laws. ${ }^{2}$ In particular the "Code of Conduct" included

(i) a limitation of the advertising time on each channel to 9.5 minutes per hour in prime time and sixteen minutes per hour at all the other times

(ii) a limitation of the number of commercials per hour

(iii) a limitation of the number of advertised products in one hour.

The DOJ argued that these rules had the purpose and effect of manipulating the supply of commercial television time with the result that the price for advertisements had been raised. This would violate the Section 1 of the Sherman Act. As a result of the allegation and subsequent legal judicial proceedings, the NAB voluntarily abandoned its "Code of Conduct" in the year 1983. From an economic point of view, these advertising ceilings cannot be explained without pecuniary externalities. In the existing models, like Anderson and Coate (2005), collusion between the channels results in an agreement that every channel has to offer a minimum level of advertising because the equilibrium advertising level is below the collusive advertising level. Hence, collusion would not lead to a "Code of Conduct" that determines a maximum advertising level.

In order to analyze a two-sided market with both externalities, we build a model where platforms are symmetrically located on a Salop circle. They simultaneously decide how much time they offer to advertisers on their channels. The consumers are uniformly distributed on the circle, dislike advertisements, and have to choose

\footnotetext{
${ }^{2}$ Campell (1999)
} 
exactly one platform. Advertisers want to advertise their products. Therefore, they have a certain willingness to pay for "viewer-time" units. In our model the crucial ingredient is that the advertisers' aggregated demand function for viewertime units is decreasing. We show that one can derive such a property from two kinds of microfoundations. One way is to assume that advertisers have a convex cost function for producing the advertised good. A second way is to assume wordof-mouth advertising. ${ }^{3}$

In this paper we show that advertising can either have the property of a strategic substitute or of a strategic complement. This is in contrast to the existing literature like Anderson and Coate (2005). By using linear demand functions, we are able to solve the model analytically. We show that advertising exhibits the property of a strategic complement (substitute) in the market equilibrium if the differentiation between the platforms is low (high). In addition, we show that market entry can lead to more or less advertising on each channel. This is also in contrast to the existing literature. For example Choi (2003) shows that market entry unambiguously decreases the advertising level. Furthermore, we get the surprising result that market entry can increase the incumbents' profits. This is the case if the equilibrium advertising level is above the per viewer revenue maximizing advertising level. Due to the pecuniary externalities, market entry can shift the equilibrium advertising level in the direction of the per viewer revenue maximizing advertising level. This increases the profits per viewer. If this increase of the profit is higher than the decrease of the profit through the loss of viewers, then the incumbents are better off. Moreover, we show that entry has ambiguous effects from a welfare point of view. A social planer has to consider the following trade-off. On the one hand, more advertising increases the surplus of the advertisers. On the other hand, more advertising decreases viewers' utility. We show that perfect competition can drive the equilibrium advertising level below the socially optimal advertising level. Therefore, perfect competition may not be desirable even if the sum of viewers' transportation costs decrease with market entry.

This paper is related to the literature on two-sided markets. The basic literature describes the interaction between two groups that are mediated by a platform

\footnotetext{
${ }^{3}$ In the Appendix we consider a third microfoundation, namely switching viewers.
} 
(see e.g. Armstrong (2005), Cauillad and Jullien (2003), Nocke et.al. (2004), Rochet and Tirole $(2003,2004)$ ). The media market, and particularly the broadcasting market, is a subclass of such a two-sided market because it has a special feature. One side, namely advertisers, likes the interaction with the second side, namely viewers. At the same time viewers dislike the interaction with advertisers. ${ }^{4}$

Several papers have addressed this peculiarity of the broadcasting market. Usually the advertising market is modelled in such a way that advertisers have no bargaining power and take the decisions (advertising prices or quantities) of the channels as given ${ }^{5}$ and viewers dislike advertising. ${ }^{6}$ Papers that consider price competition are Reisinger (2004), Nilssen and Sorgard (2001) and Kind et.al. (2005). Given the structure of the US TV advertising market, we argue that the assumption of quantity competition seems to better fit reality. Papers that consider quantity competition are e.g. Anderson and Coate (2005), Anderson (2005), Gabszewicz et.al. (2004), Crampes et.al. (2004), Choi (2003), Peitz and Valetti (2004), and Kohlschein (2004). All papers that consider quantity competition have a similar microfoundation of advertising, which we describe in Section 3.3. Hereafter, we refer to these papers as the existing literature. Anderson and Coate (2005) prove that there could be too much or too little advertising compared to the social optimum. Anderson (2005) considers how advertising ceilings influence the quality decisions of the broadcasting channels. Choi (2003) looks at the endogenous number of broadcasting channels. Kohlschein (2004) considers competition between public and private channels. Gabszewicz et.al. (2004), like Peitz and Valetti (2004), consider the location decision of the channels. Crampes et.al. (2004) allow for (dis)economies of scale of advertising. By including pecuniary externalities between the platforms, we extend the framework that is used in the existing literature.

We will proceed as follows. In the next section we set up the model. In Section 3 we provide different microfoundations for pecuniary externalities. In Section 4

\footnotetext{
${ }^{4} \mathrm{By}$ contrast, there is often the assumption that viewers like advertising in models concerned with the press industry (see e.g. Häckner and Nyberg (2000)).

${ }^{5}$ One exception is the work of Gal-Or and Dukes $(2003,2006)$ where platforms and advertisers bargain.

${ }^{6}$ One paper that differs is Cunningham and Alexander (2004). They use a completely different modelling approach and incorporate competition in the advertising market, but do not explicitly consider competition for the viewers.
} 
we solve the model and derive the symmetric market equilibrium. In Section 5 we determine whether advertising exhibits the property of a strategic substitute or complement. In Section 6 we consider the effects of market entry on platforms' profits and on welfare. Section 7 concludes.

\section{The Model}

There are three kinds of agents in our model: viewers, broadcasting channels and advertisers.

Viewers of a broadcasting channel, who are potential consumers of the advertisers, can watch one channel at a certain point in time. In the two-sided market framework this means that they singlehome. The viewers are heterogeneous with respect to their preferences of watching a certain channel. Hence, we assume that they are uniformly distributed on a Salop circle. We denote by $x$ the location of a viewer on this circle. The mass of consumers is normalized to 1 . This leads to the following utility of a viewer that watches channel $i$ and is located at 0 :

$$
U(x)=B-w_{i}-t x .
$$

We denote by $w_{i}$ the advertising level of channel $i$. Due to the fact that advertising is annoying, $w_{i}$ enters the utility function with a negative sign. Furthermore, we denote by $t x$ the viewer's disutility from not watching exactly his preferred programm. $B$ is a constant which ensures that the utility is always positive. We normalize the outside option to $\underline{U}=0$ and hence the market is always covered. Furthermore, we assume that the $N$ broadcasting channels are located equidistantly on the Salop circle. Therefore, the marginal consumer between channel $i$ and $j$ for $w_{j}-\frac{t}{N} \leq w_{i} \leq w_{j}+\frac{t}{N}$ is

$$
B-w_{i}-t x=B-w_{j}-t\left(\frac{1}{N}-x\right) .
$$

The marginal consumer between channel $i$ and $l$ for $w_{l}-\frac{t}{N} \leq w_{i} \leq w_{l}+\frac{t}{N}$ is

$$
B-w_{i}-t x=B-w_{l}-t\left(\frac{1}{N}-x\right) .
$$


Hence, channel $i$ faces the following demand function

$$
D_{i}\left(w_{i}, w_{j}, w_{l}\right)=2 x=\frac{1}{N}+\frac{w_{j}-w_{i}}{2 t}+\frac{w_{l}-w_{i}}{2 t}
$$

for $w_{l}-\frac{t}{N} \leq w_{i} \leq w_{l}+\frac{t}{N}$ and $w_{j}-\frac{t}{N} \leq w_{i} \leq w_{j}+\frac{t}{N}$.

Using symmetry between channels $j$ and $l$ yields

$$
D_{i}=\frac{1}{N}+\frac{w_{l}-w_{i}}{t} \text { for } w_{l}-\frac{t}{N} \leq w_{i} \leq w_{l}+\frac{t}{N} .
$$

Broadcasting channels try to attract viewers in order to sell time of these viewers to the advertisers. Therefore, the profit function of a channel $i$ is

$$
\pi_{i}=D_{i} w_{i} p
$$

By $p$ we denote the "viewer-time" unit price. If one multiplies the number of viewers of a channel $\left(=D_{i}\right)$ by the advertising time $\left(=w_{i}\right)$, then this yields the channel $i$ 's supply of viewer-time units. This supply multiplied by the price per viewer-time unit yields the channel $i$ 's profit. We assume zero marginal costs for serving a viewer. This is due to the public good nature of broadcasting. Furthermore, we abstract from fixed costs. The channels choose $w_{i}$ in order to maximize their profits, taking as given the other channels advertising levels.

The advertisers advertise in order to inform viewers about their products. Therefore, they have a willingness to pay for viewer-time units in order to reach consumers. We assume that viewer-time units are a homogenous good, which we justify with our microfoundation. Furthermore, we assume that the advertisers' inverse demand function for viewer-time units is decreasing in the total supply of viewer-time units

$$
\begin{gathered}
p=p\left(w_{1} D_{1}, w_{2} D_{2}, \ldots, w_{N} D_{N}\right), \\
\frac{\partial p}{\partial w_{i} D_{i}}<0, \forall i \in\{1,2, \ldots, N\} .
\end{gathered}
$$


We are able to solve the model analytically with the following linear demand function, which we will use throughout the paper.

$$
p=A-\sum_{k=1}^{N} w_{k} D_{k} .
$$

To model the television market, we choose the following time structure. Firstly, the channels choose simultaneously their advertising levels $w_{i}{ }^{7}$ Secondly, the viewers decide which channel to watch. Thirdly, a price $p$, which is determined by a walrasian auctioneer, clears the market in such a way that the supply of viewertime units is equal to the advertisers' demand for viewer-time units.

We think that this is the appropriate time structure to model the television market. Goettler (1998) describes how the television advertising market works in the US. The broadcasting channels present their programm schedule in the so called "Upfront Market", which is in May for the upcoming season in September. $70 \%$ to $80 \%$ of the advertising time is sold during this upfront market at a market clearing price. ${ }^{8}$ The rest is sold in the "scatter market" some weeks before the advertising slot is aired or is used to promote the channel's own movies and shows.

\section{Microfoundation of the Advertisers' Demand Function}

The main difference to the existing literature is our inverse demand function of the advertisers. In the existing literature it is assumed that the price of a viewertime unit on channel $i$ is only decreasing in $w_{i}$, but independent of $D_{i}, w_{j}$ and $D_{j}, \forall j \in\{1,2, \ldots, N\} / i$

$$
p_{i}=p_{i}\left(w_{i}\right),
$$

\footnotetext{
${ }^{7}$ Consider e.g. that a channel decides to produce, or to buy a sitcom, that is 25 minutes long. If the channel starts this sitcom at $8 \mathrm{pm}$ and starts the next show on the channel at $8.30 \mathrm{pm}$, then the channel commits to 5 minutes advertising.

${ }^{8}$ To quote from one report about the upfront market: "If supply exceeds demand in the network Upfront, then let the suppliers battle among themselves to the advantage of advertisers." Source: Jack Myers Report, April 5, 2004 (www.jackmyers.com)
} 


$$
\begin{aligned}
& \frac{\partial p_{i}}{\partial w_{i}}<0, \frac{\partial p_{i}}{\partial D_{i}}=0, \\
& \frac{\partial p_{i}}{\partial D_{j}}=0, \frac{\partial p_{i}}{\partial w_{j}}=0 \forall j \in\{1,2, \ldots, N\} / i .
\end{aligned}
$$

Hence, no pecuniary externalities appear because a change in $w_{i}$ does not influence the price $p_{j}$ on a channel $j$. In the following we explain the microfoundation of the existing literature. Afterwards we show how one derives pecuniary externalities due to simple modifications of the existing microfoundation. ${ }^{9}$ Therefore, we think that having no pecuniary externalities is an artefact of the particular microfoundation that is used in the existing literature. Hence, in our opinion pecuniary externalities should be the expected case.

Following Bagwell (2003), we can distinguish between three views of advertising: the persuasive view, the informative view, and the complementary view. As the existing literature, we concentrate on the informative view. In the existing models an advertiser $g$ produces one product with constant marginal costs. This product has no substitute. Viewers are unaware of this product and advertising has the function of informing a viewer about the existence of this product. By seeing a commercial of an advertiser $g$, a viewer learns about the existence of this product. Each viewer has, by assumption, the same valuation $v_{g}$ for one unit of a product of firm $g$. A viewer's valuation is zero for all further units of a product. This is common knowledge. Obviously, an advertiser asks a price $v_{g}$ for his product. Hence, a viewer buys only once one unit of a product after seeing the corresponding commercial. Given this setup, each advertiser wants to reach each viewer exactly once. Every additional contact is useless because the consumer is already informed about the product and never buys a second unit of this product. Furthermore, it is assumed that the consumers' valuation $v_{g}$ is different for each kind of product $\left(v_{g} \in[\underline{v} ; \bar{v}]\right)$. This assumption leads to a decreasing aggregated inverse demand function for advertising on one channel without generating pecuniary externalities between the channels. For example, suppose a price of 10 for one viewer-time unit on a certain channel. Then only the advertisers that have a

\footnotetext{
${ }^{9}$ In the following we only consider a microfoundation with a convex cost function or with word-ofmouth advertising. A third possibility are switching viewers. However, given switching viewers, we are not able to derive that viewer-time units are a homogenous good. We can only justify pecuniary externalities. Therefore, we consider the case of switching viewers in the Appendix.
} 
product $v_{g} \geq 10$ advertise on this channel $i$. If another channel increases his advertising level, then this does not influence the willingness to pay of the advertisers to advertise on channel $i$ because the revenue from advertising remains constant. Thus, 10 remains the equilibrium price on channel $i$ and no pecuniary externalities appear in this existing setup.

In order to derive microfoundations for the pecuniary externalities, we modify this framework. We assume that all advertisers are homogenous in such a way that each advertiser has one kind of product for that no substitute exists. Furthermore, a consumer has the valuation $v$ for exactly one unit of each product. As in the existing literature, the willingness to pay is zero for further units of a product. Viewers are unaware of the existence of an advertiser's product. Advertising has the function of informing the viewers about its existence. In contrast to the framework above, we do not assume that a viewer learns for sure that the product exists after he has seen the product's commercial. In fact, we take into account that viewers might be inattentive. Therefore, we assume that a viewer gains knowledge with a certain probability $z$ after seeing an advertisement. This probability increases in the length of the commercial. Given the assumption of homogenous advertisers, we can concentrate on one representative advertiser $g$.

In order to derive the advertiser $g$ 's demand function for viewer-time units, we write down his profit function

$$
\pi_{g}=v \sum_{k=1}^{N} z\left(w_{g k}\right) D_{k}-C\left(\sum_{k=1}^{N} z\left(w_{g k}\right) D_{k}\right)-\sum_{k=1}^{N} p_{k} w_{g k} D_{k} .
$$

By $w_{g i}$ we denote the advertiser $g$ 's advertising level on channel $i$. The advertising level $w_{g i}$ determines the probability $z=z\left(w_{g i}\right)$ with which a consumer gets aware of the advertiser's product if he watches channel $i$. If a viewer becomes aware of the product, we know that his product valuation is $v$. Obviously, the optimal price that an advertiser $g$ should ask for his product is $v$. Hence, the first term displays the revenue of selling the advertised good, the second the costs of producing the advertised good, and the third the costs of advertising. 
Microfoundation 1: Convex Cost Function for Producing the Advertised Good

Suppose that the probability $z$ increases linearly in $w_{g i}$

$$
z\left(w_{g i}\right)=\frac{w_{g i}}{A} .
$$

$A$ is a parameter that normalizes the probability $z\left(w_{g i}\right) \in[0 ; 1]$. Hence, the advertiser $g$ sells $\sum_{k=1}^{N} \frac{w_{g k}}{A} D_{k}$ units at a price of $v$.

Furthermore, suppose that the advertiser has a strictly convex cost function for producing the advertised $\operatorname{good}^{10}$

$$
C^{\prime}\left(\sum_{k=1}^{N} \frac{w_{g k}}{A} D_{k}\right) \geq 0 ; \quad C^{\prime \prime}\left(\sum_{k=1}^{N} \frac{w_{g k}}{A} D_{k}\right)>0 .
$$

This yields the following profit function

$$
\pi_{g}=v \sum_{k=1}^{N} \frac{w_{g k}}{A} D_{k}-C\left(\sum_{k=1}^{N} \frac{w_{g k}}{A} D_{k}\right)-\sum_{k=1}^{N} p_{k} w_{g k} D_{k}
$$

The advertiser maximizes his profit by his choice of $w_{g i} D_{i}$. Therefore, maximizing the advertiser $g$ 's profit function with respect to $w_{g i} D_{i}$ leads to his willingness to pay for the last viewer-time unit on channel $i^{11}$

$$
p_{i}=\frac{v}{A}-C^{\prime} .
$$

We see that viewer-time units are a homogenous good because $C^{\prime}$ does not depend on the particular channel $i$. Therefore, the prices for viewer-time units have to be the same on all channels

$$
p_{i}=p \forall i \in\{1,2, \ldots, N\} .
$$

\footnotetext{
${ }^{10}$ Armstrong (2004) mentions this idea in the context why the advertisers' payoffs need not to be constant. Cunningham and Alexander (2004) also use a convex cost funtion in their setup.

${ }^{11}$ The SOC is globally satisfied.
} 
Furthermore, the inverse demand function $p=\frac{v}{A}-C^{\prime}$ is decreasing in $w_{g i} D_{i}$

$$
\frac{\partial p}{\partial w_{g i} D_{i}}=-C^{\prime \prime}<0, \forall i \in\{1,2, \ldots, N\} .
$$

Summing up, we see that the broadcasting channels have pecuniary externalities given increasing marginal costs for producing the advertised good. The intuition for the pecuniary externality is obvious. If an advertiser $g$ increases his advertising level on a channel, then the advertising firm $g$ sells more products. Hence, the firm $g$ 's willingness to pay for the last viewer-time unit decreases on all channels because his marginal costs are higher compared to the situation before.

In order to derive the linear demand function

$$
p=A-\sum_{k=1}^{N} w_{k} D_{k}
$$

suppose that a consumer has the valuation $v=A^{2}$. Furthermore, we assume that the cost function for producing the advertised good is

$$
C\left(\sum_{k=1}^{N} z_{g}\left(w_{g k}\right) D_{k}\right)=\frac{A^{2}}{2}\left(\sum_{k=1}^{N} \frac{w_{g k}}{A} D_{k}\right)^{2} .
$$

Plugging into the profit function yields

$$
\pi_{g}=A^{2} \sum_{k=1}^{N} \frac{w_{g k}}{A} D_{k}-\frac{A^{2}}{2}\left(\sum_{k=1}^{N} \frac{w_{g k}}{A} D_{k}\right)^{2}-\sum_{k=1}^{N} p w_{g k} D_{k} .
$$

Maximizing with respect to $w_{g i} D_{i}$ and solving for $p$ leads to

$$
p=A-\sum_{k=1}^{N} w_{g k} D_{k} .
$$


Summing up over all $M$ advertisers yields the aggregated inverse demand function

$$
p=A-\sum_{k=1}^{N} w_{k} D_{k}
$$

\section{Microfoundation 2: Word-of-Mouth Advertising}

Another way to give a microfoundation is word-of-mouth advertising. In the following we assume that the marginal costs for producing the advertised good are constant. We normalize these costs to zero without loss of generality.

The idea behind the word-of-mouth advertising setup is that a viewer can learn about the existence of a certain product in two different ways. On the one hand, he can become aware of the product through advertising. On the other hand, he can become aware of it by recognizing that another person has bought this product. In order to capture this idea, we extend the model by introducing two periods. In the first period the viewers are exposed to the advertising spots of the different firms. Depending on the length of advertisement $w_{g i}$, they buy the product of advertiser $g$ with probability $z\left(w_{g i}\right)=\frac{w_{g i}}{A}$. In the second period we assume that always pairs of viewers meet each other. In particular each viewer meets one other viewer. A viewer sees whether the other viewer has bought a product of firm $g$ or not. Suppose that a viewer has not become aware of the product in the first period and meets a viewer in the second period who has bought the product in the first period. Given this, the non-buyer of the first period becomes aware of the product and also buys it. Such a constellation, where a non-buyer meets a buyer, is the only possibility how sales occur in the second period. Formalizing this idea leads to the following profit function of an advertiser $g$

$$
\pi_{g}=v\left[\sum_{k=1}^{N} D_{k} \frac{w_{g i}}{A}+\sum_{k=1}^{N} D_{k}\left(1-\frac{w_{g k}}{A}\right) \sum_{j=i}^{N} D_{j} \frac{w_{g j}}{A}\right]-\sum_{k=1}^{N} p_{k} w_{g k} D_{k} .
$$

Maximizing with respect to $w_{g k} D_{k}$ leads to 


$$
p_{k}=v(\overbrace{\frac{1}{A}}^{\text {Effect } 1}+\overbrace{\left(-\frac{1}{A} \sum_{k=1}^{N} D_{k} \frac{w_{g k}}{A}\right)}^{\text {Effect } 2}+\overbrace{\left.\frac{1}{A} \sum_{k=1}^{N} D_{k}\left(1-\frac{w_{g k}}{A}\right)\right)}^{\text {Effect } 3} .
$$

We see that if channel $k$ increases his supply of viewer-time units, then three effects appear:

Effect 1: The probability increases that a viewer of this channel buys the product in the first period.

Effect 2: The probability decreases that a viewer of this channel buys the product in the second period 2. This is due to the fact that it is less likely that a viewer of channel $k$ does not buy in the first period.

Effect 3: The probability increases that a non-buyer meets a buyer in the second period.

The sum of the three effects multiplied by the price $v$ yields the marginal revenue of advertising on channel $k$. This is the advertiser's willingness to pay for the last viewer-time unit on channel $k$. We see that viewer-time units are a homogenous good because the willingness to pay for the last viewer-time unit is the same on all channels

$$
p=p_{i} \forall i \in\{1, \ldots, N\}
$$

Furthermore, simplifying Equation 26 yields

$$
p=2 \frac{v}{A}\left(1-\sum_{i=1}^{N} D_{i} \frac{w_{g i}}{A}\right) .
$$

We see that the inverse demand function is decreasing in $w_{g i} D_{i}$

$$
\frac{\partial p}{\partial w_{g i} D_{i}}=-2 \frac{v}{A^{2}}<0 \forall i \in\{1,2, \ldots, N\} .
$$


In particular there are two reasons why the willingness to pay decreases if the supply increases:

Reason 1: It is less attractive to increase the probability that a viewer buys in the first period because the probability that he meets a buyer in the second period increases $\left(=-\frac{1}{A^{2}}\right)$.

Reason 2: It is less attractive to increase the probability that a viewer buys the product in the first period because the probability that this buyer meets a non-buyer in the second period decreases $\left(=-\frac{1}{A^{2}}\right)$.

As the microfoundation with a convex cost function, this mircrofoundation yields the linear demand function with which we work later on. Suppose that the consumers' valuation is

$$
v=\frac{A^{2}}{2} .
$$

This yields the following profit of advertiser $g$

$$
\pi_{g}=\frac{A^{2}}{2}\left[\sum_{k=1}^{N} D_{k} \frac{w_{g k}}{A}+\sum_{k=1}^{N} D_{k}\left(1-\frac{w_{g k}}{A}\right) \sum_{j=1}^{N} D_{j} \frac{w_{g j}}{A}\right]-\sum_{k=1}^{N} p w_{g k} D_{k} .
$$

Maximizing with respect to $w_{g k} D_{k}$ leads to

$$
p=A-\sum_{k=1}^{N} w_{g k} D_{k} .
$$

Summing up over all $M$ advertisers yields the linear inverse demand function

$$
p=A-\sum_{k=1}^{N} w_{k} D_{k}
$$




\section{Competition in Advertising Levels}

In this section we look at the profit maximization problem of the channels and we solve the model for the symmetric market equilibrium. The broadcasting channel $i$ has the following maximization problem

$$
\max _{w_{i}} \pi_{i}=D_{i} w_{i} p
$$

with

$$
D_{i}=\frac{1}{N}+\frac{w_{j}-w_{i}}{2 t}+\frac{w_{l}-w_{i}}{2 t} \text { for } w_{j}-\frac{t}{N} \leq w_{i} \leq w_{j}+\frac{t}{N}
$$

and

$$
p=A-\sum_{k=1}^{N} w_{k} D_{k} .
$$

The first order condition of channel $i$ can be written as

$$
\frac{\partial \pi_{i}}{\partial w_{i}}=\frac{\partial D_{i}}{\partial w_{i}} p w_{i}+D_{i} \frac{\partial\left(p w_{i}\right)}{\partial w_{i}}=0 .
$$

Hence, the optimal advertising level solves the trade-off between losing the revenue from a viewer and increasing the revenue per viewer.

Another possibility to express the first order condition of channel $i$ is

$$
\begin{aligned}
& \frac{\partial \pi_{i}}{\partial w_{i}}=\overbrace{D_{i} p}^{\text {Scale Up Effect }}+\overbrace{\frac{\partial D_{i}}{\partial w_{i}} w_{i} p}^{\text {Quantity Effect }}+ \\
& \text { Price Effect } \\
& \overbrace{D_{i} w_{i} \frac{\partial p}{\partial w_{i}}+D_{i} w_{i} \frac{\partial p}{\partial D_{i}} \frac{\partial D_{i}}{\partial w_{i}}+D_{i} w_{i}\left(\frac{\partial p}{\partial D_{j}} \frac{\partial D_{j}}{\partial w_{i}}+\frac{\partial p}{\partial D_{l}} \frac{\partial D_{l}}{\partial w_{i}}\right)}=0 .
\end{aligned}
$$

To understand this FOC, we consider a "One-Sided Market" maximization problem. Usually the marginal revenue, $R=p q$, exhibits in a "One-Sided Market", depending on the kind of strategic variable, a simple trade-off:

- Suppose that the quantity $q$ is the strategic variable, so $R(q)=p(q) q$. If a firm increases $q$, then it sells one more unit (=Scale Up Effect), but every unit at a smaller price (=Price Effect) 


$$
\frac{\partial R}{\partial q}=\overbrace{p}^{\text {Scale Up Effect }}+\overbrace{\frac{\partial p}{\partial q} q}^{\text {Price Effect }} .
$$

- Suppose that the price $p$ is the strategic variable, so $R(p)=p q(p)$. If a firm increases $p$, then it sells all units at a marginal higher price $(=$ Scale Up Effect), but only a smaller number of units (=Quantity Effect)

$$
\frac{\partial R}{\partial p}=\overbrace{q}^{\text {Scale Up Effect }}+\overbrace{\frac{\partial q}{\partial p} p}^{\text {Quantity Effect }} .
$$

In our two-sided-market setup we have the combination of a price and a quantity competition. The advertising level is a kind of price for the viewers. For the advertisers it is, multiplied by the number of viewers, the supply. This is reflected in the first order condition. There we have, beside the "Scale Up Effect", the "Price Effect" as well as the "Quantity Effect". For the "Price Effect" we have to take into account that if a channel $i$ increases its advertising level, then it directly increases the supply of viewer-time units (=direct effect). But furthermore, it changes the distribution of the viewers on the channels. This changes the supply of viewer-time units, which has a further impact on the price (=indirect effect).

$$
\frac{\partial p}{\partial w_{i}}=\overbrace{\frac{\partial p}{\partial w_{i}}}^{\text {direct effect }}+\overbrace{\frac{\partial p}{\partial D_{i}} \frac{\partial D_{i}}{\partial w_{i}}+\frac{\partial p}{\partial D_{j}} \frac{\partial D_{j}}{\partial w_{i}}+\frac{\partial p}{\partial D_{l}} \frac{\partial D_{l}}{\partial w_{i}}}^{\text {indirect effect }}
$$

with $l$ and $j$ as the neighbors of $i$.

In order to derive the symmetric market equilibrium, we look at the corresponding first order condition

$$
\left.\frac{\partial \pi_{i}}{\partial w_{i}}\right|_{w_{1}^{*}=w_{2}^{*}=\ldots=w_{N}^{*}}=\frac{1}{N} p^{*}-\frac{1}{t} w_{i}^{*} p^{*}+\frac{1}{N} w_{i}^{*} \frac{\partial p^{*}}{\partial w_{i}^{*}}=0 .
$$


Using the specified demand functions, we can solve for the symmetric equilibrium advertising level $w_{i}^{*}$.

Proposition 1. Assume that the viewers' demand function is (with $-i$ as the symmetric neighbors of $i$ )

$$
D_{i}=\frac{1}{N}+\frac{w_{-i}-w_{i}}{t} \text { for } w_{-i}-\frac{t}{N} \leq w_{i} \leq w_{-i}+\frac{t}{N}
$$

and that the advertisers' inverse demand function is

$$
p=A-\sum_{k=1}^{N} D_{k} w_{k} .
$$

The advertising level

$$
w_{i}^{*}=\frac{\left(N t+t+N^{2} A\right)-\sqrt{\left(N t+t+N^{2} A\right)^{2}-4 N^{3} t A}}{2 N^{2}}
$$

is the unique symmetric Nash-Equilibrium.

Proof. See Appendix.

\section{Has Advertising the Property of a Strate- gic Substitute or Complement?}

In the existing literature advertising has the property of a strategic complement. In these setups advertising is a kind of price for the consumers and no pecuniary externality appears. Hence, as in price competition, each channel decreases his advertising level if another channel decreases his advertising level. In the following we show that it is not obvious that advertising has the property of a strategic complement given pecuniary and participation externalities.

For simplicity we consider a duopoly $(N=2)$. We denote the two channels by $\{i ;-i\}$. Whether we have strategic substitutes or complements depends on the sign of

$$
\frac{\partial^{2} \pi_{i}}{\partial w_{i} \partial w_{-i}}=\frac{\partial p}{\partial w_{-i}} \frac{\partial\left(D_{i} w_{i}\right)}{\partial w_{i}}+\frac{\partial D_{i}}{\partial w_{-i}} \frac{\partial\left(p w_{i}\right)}{\partial w_{i}}+w_{i}\left[\frac{\partial^{2} D_{i}}{\partial w_{i} \partial w_{-i}} p+D_{i} \frac{\partial^{2} p}{\partial w_{-i} \partial w_{i}}\right] \lesseqgtr 0 .
$$

We see that channel $-i$ influences the price function $p$ and the demand function $D_{i}$. This has four consequences: 
- it changes the price $p\left(=\frac{\partial p}{\partial w_{-i}}\right)$

- it changes the number of viewers of channel $i\left(=\frac{\partial D_{i}}{\partial w_{-i}}\right)$

- it changes the impact of firm $i$ on the price $p\left(=\frac{\partial^{2} p}{\partial w_{i} \partial w_{-i}}\right)$

- it changes the impact of firm $i$ on the number of viewers $D_{i}\left(=\frac{\partial^{2} D_{i}}{\partial w_{i} \partial w_{-i}}\right)$

The change in the price $p$ influences the incentive to change the quantity of viewer-time units $\left(\frac{\partial\left(D_{i} w_{i}\right)}{\partial w_{i}}\right)$. If the price decreases, then it gets less desirable to have more viewer-time units. The change in the number of viewers $D_{i}$ changes the incentive to change the revenue per viewer $\frac{\partial\left(p w_{i}\right)}{\partial w_{i}}$. Given more viewers, it gets more preferable to have a high revenue per viewer. Furthermore, the changes of the impact of the advertising level on the audience size and on the price have an additional effect on the incentives to change the advertising level. The number of viewers that one loses with a higher advertising level changes. Moreover, the impact of an increase in the advertising level on the price changes.

With our specified viewers' demand function, we have that $\frac{\partial D_{i}}{\partial w_{-i}}=\frac{1}{t}$ given $w_{-i}-\frac{t}{2} \leq w_{i} \leq w_{-i}+\frac{t}{2}$ and $\frac{\partial^{2} D_{i}}{\partial w_{i} \partial w_{-i}}=0$ because

$$
D_{i}=\left\{\begin{array}{ccc}
1 & \text { if } & w_{i}<w_{-i}-\frac{w_{-i}}{t} \\
\frac{1}{2}+\frac{w_{-i}-w_{i}}{t} & \text { if } & w_{-i}-\frac{t}{2} \leq w_{i} \leq w_{-i}+\frac{t}{2} \\
0 & \text { if } & w_{-i}+\frac{t}{2}<w_{i}
\end{array}\right.
$$

Furthermore, given the specified advertisers' demand function $p=A-\sum_{k=1}^{N} D_{k} w_{k}$, the cross derivative is $\frac{\partial^{2} p}{\partial w_{i} \partial w_{-i}}=-\frac{2}{t}$ for $w_{-i}-\frac{t}{2} \leq w_{i} \leq w_{-i}+\frac{t}{2}$. We cannot make any statement about the sign of $\frac{\partial p}{\partial w_{i}}$ and $\frac{\partial p}{\partial w_{-i}}$ without knowing the actual values of $w_{i}$ and $w_{-i}$ because

$$
\frac{\partial p}{\partial w_{i}}=\left\{\begin{array}{ccc}
-1 & \text { if } & w_{i}<w_{-i}-\frac{t}{2} \\
-D_{i}+\frac{w_{i}}{t}-\frac{w_{-i}}{t} \leq 0 & \text { if } & w_{-i}-\frac{t}{2} \leq w_{i} \leq w_{-i}+\frac{t}{4} \\
-D_{i}+\frac{w_{i}}{t}-\frac{w_{-i}}{t}>0 & \text { if } & w_{-i}+\frac{1}{4} t<w_{i} \leq w_{-i}+\frac{t}{2} \\
0 & \text { if } & w_{-i}+\frac{t}{2}<w_{i}
\end{array}\right.
$$


Hence, it is possible that the price per viewer-time unit increases if a channel extends his advertising level. To illustrate this point, suppose two channels. Assume that channel 1 has a higher advertising level than channel 2 in such a way that channel 1 has only "one" remaining viewer. If channel 1 increases his advertising level even further, then this last viewer switches to channel 2. Thus, the higher advertising level of channel 1 decreases the aggregated supply of viewertime units and increases the market price $p$.

Let us now determine the reaction function of channel $i$ : $w_{i}^{*}=w_{i}^{*}\left(w_{-i}\right)$. In order to do this, we have to distinguish between three cases:

Case 1: $w_{-i}>w_{-i}^{H}=\frac{A}{2}+\frac{t}{2}$

Suppose that $w_{-i}>\frac{A}{2}+\frac{t}{2}$. We can calculate that $w_{i}=\frac{A}{2}$ maximizes channel $i$ 's revenue per viewer. Furthermore, we have that

$$
D_{i}\left(w_{i}=\frac{A}{2} ; w_{-i} \geq w_{-i}^{H}\right)=1 .
$$

Hence, $w_{i}=\frac{A}{2}$ has to be channel $i$ 's best response. If channel $i$ chooses $w_{i}=\frac{A}{2}$, then he all viewers watch his program and he has the highest possible revenue per viewer.

Case 2: $w_{-i}^{H} \geq w_{-i} \geq w_{-i}^{C}=\frac{7}{4} t+\frac{1}{2} A-\frac{1}{4} \sqrt{\left(25 t^{2}+4 A t+4 A^{2}\right)}$

In this second case $w_{-i}$ is not high enough to allow channel $i$ to choose $w_{i}=\frac{A}{2}$ and still to have $D_{i}=1$. Given this $w_{-i}$, the profit of channel $i$ decreases in $w_{i}$ $\left(\frac{\partial \pi_{i}}{\partial w_{i}}<0\right)$. A higher advertising level leads to a lower number of viewers and the change in the revenue per viewer cannot make up for this loss. Hence, reducing the advertising level increases the profit as long as $D_{i}<1$. Therefore, we derive a corner solution $w_{i}^{*}\left(w_{-i}\right)=w_{-i}-\frac{t}{2}$ where $D_{i}=1$.

Case 3: $w_{-i}<w_{-i}^{C}=\frac{7}{4} t+\frac{1}{2} A-\frac{1}{4} \sqrt{\left(25 t^{2}+4 A t+4 A^{2}\right)}$

In Case 3 we have an interior solution. The reaction function can be calculated and is 


$$
\begin{array}{r}
w_{i}^{\text {Case } 3}=\left(1+\frac{1}{48} t^{2}+\frac{5}{24} w_{-i} t-\frac{1}{6} A t+\frac{1}{16} w_{-i}^{2}\right)\left[\frac{3}{64} t w_{-i}^{2}-\frac{1}{16} w_{-i} A t-\frac{1}{64} w_{-i}^{3}+\right. \\
\frac{1}{576}\left[1440 t^{4} w_{-i} A+1296 A t w_{-i}^{4}-432 A^{2} t^{2} w_{-i}^{2}+2376 w_{-i}^{3} t^{2} A\right. \\
-5760 w_{-i} t^{3} A^{2}+7632 t^{3} A w_{-i}^{2}-3540 t^{3} w_{-i}^{3}-3 t^{6}-90 t^{5} w_{-i}-927 t^{4} w_{-i}^{2}-576 t^{4} A^{2}- \\
\left.\left.2052 t^{2} w_{-i}^{4}-1296 w_{-i}^{5} t+1536 A^{3} t^{3}+72 t^{5} A\right]^{\frac{1}{2}}\right]^{\frac{1}{3}}+\frac{1}{4} t+\frac{3}{4} w_{-i}
\end{array}
$$

We summarize these findings in the following proposition.

Proposition 2. In a duopoly with

$$
D_{i}=\left\{\begin{array}{clc}
1 & \text { if } & w_{i}<w_{-i}+\frac{t}{2} \\
\frac{1}{2}+\frac{w_{-i}-w_{i}}{t} & \text { if } & w_{-i}-\frac{t}{2} \leq w_{i} \leq w_{-i}+\frac{t}{2} \\
0 & \text { if } & w_{-i}+\frac{t}{2}<w_{i}
\end{array}\right.
$$

and

$$
p=A-D_{i} w_{i}-D_{-i} w_{-i},
$$

the best response function $w_{i}^{*}\left(w_{-i}\right)$ of platform $i$ is

$$
w_{i}^{*}=\left\{\begin{array}{clc}
\frac{A}{2} & \text { if } & w_{-i}^{H}=\frac{A}{2}+\frac{t}{2}<w_{-i} \\
w_{-i}-\frac{t}{2} & \text { if } & w_{-i}^{C} \leq w_{-i} \leq w_{-i}^{H} \\
w_{i}^{\text {Case } 3}:=\text { interior solution } & \text { if } & w_{-i}<w_{-i}^{C}=\frac{7}{4}+\frac{A}{2}-\frac{1}{4} \sqrt{25 t^{2}+4 A t+4 A^{2}}
\end{array}\right.
$$

Proof. See Appendix.

In the first case it is obvious that advertising is neither a strategic substitute nor a strategic complement. In the second case we have, due to the corner solution, a perfect strategic complement. Whether advertising exhibits the property of a strategic complement or substitute in the case of an interior solution depends on the actual values of $w_{i}$ and $w_{-i}$. We have plotted two numerical examples to illustrate this (see Figure 1).

Given a high differentiation parameter $(t=200)$, we see that advertising can be either a strategic substitute or complement. In the corresponding equilibrium, 


\section{Strategic Substitutes or Complements?}

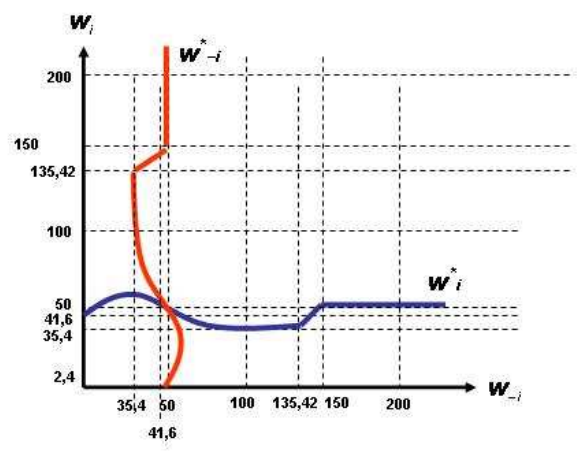

$$
A=100
$$$$
\boldsymbol{t}=\mathbf{2 0 0}
$$$$
w^{*}=w_{i}^{*}=w_{i}^{*}=50
$$

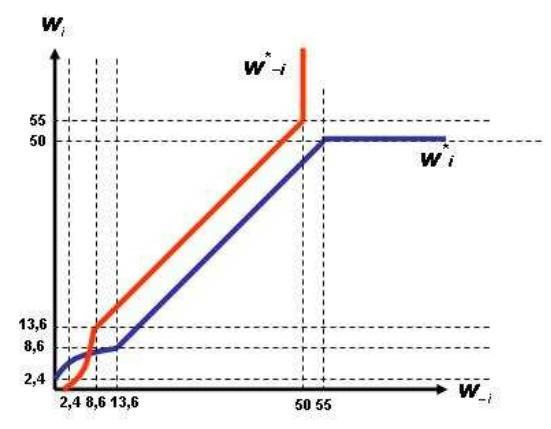

$$
\begin{gathered}
A=100 \\
t=10 \\
w^{*}=w_{i}^{*}=w_{-i}^{*}=4.87
\end{gathered}
$$

Figure 1: Strategic Substitute or Complement

$w_{i}^{*}=50$, it is a strategic substitute. In contrast, advertising exhibits the property of a strategic complement given a low differentiation $(t=10)$. However, we are able to derive analytical results whether advertising has the property of a strategic substitute or complement in a symmetric market equilibrium.

Proposition 3. In the symmetric Nash-Equilibrium of a duopoly advertising has the property of a

- strategic substitute if differentiation between platforms is relatively high $\left(t>\frac{4}{7}(2 \sqrt{2}-1) A\right)$

- strategic complement if the differentiation between platforms is relatively low $\left(t<\frac{4}{7}(2 \sqrt{2}-1) A\right)$

Proof. See Appendix. 
If one considers the advertising market, then one expects that advertising has the property of a strategic substitute because channels compete in quantities. In contrast, if one considers the viewer market, then one expects the property of a strategic complement because advertising is a kind of price for the viewers. The intuition of the proposition is the following. Due to the fact that we consider a symmetric situation, no effects that result from asymmetric advertising levels appear. Furthermore, suppose that the differentiation is high. In this case a change in the advertising level has no big impact on the viewer side and the effects of the advertising market dominate. Advertising has on the advertising market the property of a strategic substitute. Therefore, we have exactly this property if the differentiation is high. If the differentiation is low, then the opposite is true.

\section{Market Entry}

In this section we consider market entry. Given the introduction of Digital Television, broadcasting frequencies are no longer a scare resource. Governments use this to award additional licenses. This yields tougher competition between the broadcasting channels. Choi (2003) shows, by using the Anderson and Coate (2005) framework, that market entry leads to a lower advertising level and that it decreases the profits of the channels. In the following we show that this does not have to be true if we take into account pecuniary and participation externalities.

In order to do this, we start by looking at the role of the differentiation parameter $t$ and the demand parameter $A$. If the differentiation parameter $t$ increases, then the viewers' demand function gets less elastic. Furthermore, in the symmetric market equilibrium, the size of the price change $\frac{\partial p}{\partial w_{i}}$ is independent of $t$ and always $-D_{i}=-\frac{1}{N}$. Hence, an increase in $t$ leads to a higher equilibrium advertising level due to the less elastic demand function.

Additionally, if the parameter $A$ increases, then the equilibrium advertising level rises because the advertisers' willingness to pay increases. This has two effects. On the one hand, it is more attractive to increase the advertising level because the revenue per advertising unit $\left(=D_{i} p\right)$ increases. On the other hand, it 
is less attractive to increase the advertising level because the revenue per viewer increases $\left(=w_{i} p\right)$ and more advertising leads to a smaller audience size. Therefore, the two effects work in the opposite direction. One can summarize both effects in the term $p \frac{\partial\left(D_{i} w_{i}\right)}{\partial w_{i}}$. In a symmetric equilibrium we have $\frac{d p}{d w_{i}}<0$. Therefore, it has to be that $p \frac{\partial\left(D_{i} w_{i}\right)}{\partial w_{i}}>0$ in order to fulfill the first order condition. If the price $p$ increases, then the value of $\frac{\partial\left(D_{i} w_{i}\right)}{\partial w_{i}}$ has to decrease in order to satisfy the first order condition. We see that the second derivative is negative $\left(\frac{\partial^{2}\left(D_{i} w_{i}\right)}{\partial w_{i}^{2}}<0\right)$. Therefore, due to the higher price $p$, the revenue per viewer has to decrease, which the channels achieve by a higher advertising level.

We summarize these findings in the following lemma.

Lemma 1. If the differentiation between the firms increases, then the equilibrium advertising level increases

$$
\frac{\partial w_{i}^{*}}{\partial t}>0
$$

If the advertisers' demand function shifts out, then the equilibrium advertising level increases

$$
\frac{\partial w_{i}^{*}}{\partial A}>0
$$

Proof. See Appendix.

In the following we use Lemma 1 to show that market entry can either lead to a higher level of advertising or a lower level of advertising.

\section{Proposition 4.}

Market entry yields

- a higher level of advertising $\left(\frac{\partial w_{i}^{*}}{\partial N}>0\right)$ if the differentiation between the channels is relatively high $\left(t>\frac{2 N^{2} A}{2+N}\right)$;

- a lower level of advertising $\left(\frac{\partial w_{i}^{*}}{\partial N}<0\right)$ if the differentiation between the channels is relatively low $\left(t<\frac{2 N^{2} A}{2+N}\right)$.

Proof. See Appendix.

To understand the intuition behind this Proposition 4, let us consider the first order condition. In a symmetric equilibrium we have 


$$
\left.\frac{\partial \pi_{i}}{\partial w_{i}}\right|_{w_{1}^{*}=\ldots=w_{N}^{*}}=-\frac{1}{t} p w_{i}^{*}+\frac{1}{N} \frac{\partial\left(w_{i}^{*} p\right)}{\partial w_{i}}=0 .
$$

Using the implicit function theorem yields

$$
\frac{d w^{*}(N)}{d N}=-\frac{-\frac{1}{N^{2}} \frac{\partial\left(w_{i}^{*} p\right)}{\partial w_{i}}+\frac{1}{N} \frac{\partial \frac{\partial\left(p w_{i}^{*}\right)}{\partial w_{i}}}{\partial N}}{[S O C]}
$$

Therefore, we see that $\frac{d w^{*}(N)}{d N}>0$ if

$$
-\frac{1}{N^{2}} \frac{\partial\left(w_{i}^{*} p\right)}{\partial w_{i}}+\frac{1}{N} \frac{\partial \frac{\partial\left(p w_{i}^{*}\right)}{\partial w_{i}}}{\partial N}>0 .
$$

The crucial point is the change of the marginal revenue per viewer multiplied by the number of viewers $\left(D_{i}^{*} \frac{\partial\left(w_{i}^{*} p\right)}{\partial w_{i}}\right)$. If this term increases, then firms increase their advertising levels. Otherwise, they decrease their advertising levels. Note that only the mentioned term is relevant because market entry does not affect the negative effect of increasing advertising, namely losing viewers $\frac{\partial\left(\frac{\partial D_{i}}{\partial w_{i}} w_{i}^{*} p\right)}{\partial N}=0$.

After market entry each channel has a lower number of viewers in the equilibrium. This has two effects on the incentives to offer advertising. We can distinguish between them by taking the derivative of $D_{i}^{*} \frac{\partial\left(w_{i}^{*} p\right)}{\partial w_{i}}$ with respect to $N$.

On the one hand, an increase in the advertising level, which yields a higher revenue per viewer, has a smaller positive effect on the profit because it works on a smaller number of viewers. This is reflected in the term

$$
\frac{\partial D_{i}^{*}}{\partial N} \frac{\partial\left(w_{i}^{*} p\right)}{\partial w_{i}}=-\frac{1}{N^{2}} \frac{\partial\left(w_{i}^{*} p\right)}{\partial w_{i}}<0
$$

and gives an incentive to decrease the advertising level. 
On the other hand, the smaller audience size decreases the impact of channel $i$ on the price because a change in the advertising level leads to smaller change in the total supply of viewer-time units. This is reflected in the term

$$
D_{i}^{*} \frac{\partial\left(\frac{\partial\left(w_{i}^{*} p\right)}{\partial w_{i}}\right)}{\partial N}=\frac{1}{N} w_{i}^{*} \frac{1}{N^{2}}>0
$$

and gives an incentive to increase the advertising level.

Therefore, we see that a smaller audience size has two counteracting effects. The total effect depends on the size of the different effects. The dimension of the first effect decreases in the advertising level, ${ }^{12}$ and the dimension of the second effect increases in the advertising level. ${ }^{13}$ Hence, if the advertising level $w_{i}^{*}$ is relatively high, then the total effect is positive and market entry leads to an even higher advertising level. We have already seen that a higher $t$ leads to a higher $w_{i}^{*}$ (see Lemma 1). Therefore, if the differentiation is relatively high, then the equilibrium value of the advertising level is above the threshold value. Hence, the advertising level increases if market entry occurs. One may wonder why $t$ has to be higher if $A$ increases $\left(t^{\text {crit }}=\frac{2 N^{2} A}{2+N}\right.$ ) because $w_{i}^{*}$ increases if $A$ increases. But a higher $A$ has two effects. A higher $A$ leads to a higher $w_{i}^{*}$ but it increases the equilibrium value of $p^{*}$, which puts more weight on the first effect (see Equation $55)$.

To summarize, we see that the effect of market entry on the advertising level is ambiguous. Given a high level of differentiation, the advertising level increases, and given a low level of differentiation, it decreases.

In a next step we consider how market entry affects the profits of the broadcasting channels. There exists an advertising level $\widehat{w}=\frac{A}{2}$ that maximizes the revenue per viewer

$$
\begin{gathered}
\frac{\partial\left[\left(A-w_{i}\right) w_{i}\right]}{\partial w_{i}}=A-2 w_{i}=0 ; \\
\left.\left.12 \frac{d p}{d w_{i}}\right|_{w_{1}^{*}=\ldots=w_{N}^{*}}=-\frac{1}{N} ; \frac{\partial\left(\frac{\partial p}{\partial w_{i}} w_{i}^{*}+p\right.}{\partial w_{i}}\left(w_{i}^{*}\right)\right) \\
13 \frac{\partial\left(-\frac{1}{N} w_{i}^{*}+p\right)}{\partial N}=\frac{1}{N^{2}} w_{i}^{*} ; \frac{\partial\left(\frac{1}{N^{2}} w_{i}^{*}\right)}{\partial w_{i}}>0
\end{gathered}
$$




$$
\widehat{w}_{i}=\frac{1}{2} A .
$$

If the broadcasting channels colluded, then they would choose this advertising level. In the following we have to distinguish between four situations.

Situation 1. $\widehat{w}_{i}<w_{i}^{*}$ and $\frac{\partial w_{i}^{*}}{\partial N}>0 \rightarrow \frac{\partial \pi}{\partial N}<0$

In this situation the equilibrium advertising level is higher than the advertising level that maximizes the profits per viewer. Furthermore, the differentiation parameter $t$ is above the threshold level $t>\frac{2 N^{2} A}{2+N}$. Hence, market entry increases the equilibrium advertising (see Proposition 4). It is obvious that the profits of the channels decrease. Firstly, given market entry, a channel has less viewers in equilibrium because $\frac{1}{N}$ decreases in $N$. Secondly, the equilibrium advertising level increases, which yields a smaller revenue per viewer.

Situation 2. $\widehat{w}_{i}>w_{i}^{*}$ and $\frac{\partial w_{i}^{*}}{\partial N}<0 \rightarrow \frac{\partial \pi}{\partial N}<0$

In this second situation the equilibrium advertising level is lower than the advertising level that maximizes the revenue per viewer. Furthermore, the differentiation parameter $t$ is smaller than the threshold level. Hence, given market entry, the equilibrium advertising decreases. Therefore, it is obvious that the profit of an incumbent decrease with market entry.

Situation 3. $\widehat{w}_{i}<w_{i}^{*}$ and $\frac{\partial w_{i}^{*}}{\partial N}<0 \rightarrow \frac{\partial \pi}{\partial N} \lesseqgtr 0$

In this third situation the equilibrium advertising level is higher than the level that maximizes the revenue per viewer. Furthermore, given market entry, the equilibrium level of advertising decreases. Hence, the revenue per viewer increases, which has a positive effect on the profit of an incumbent. At the same time the incumbent loses viewers, which has a negative impact on the profit. To summarize, there are two counteracting effects on an incumbent's profit. Whether the profit decreases or increases depends on the size of the different effects.

$$
\pi_{i}=\left(A-w_{i}^{*}\right) w_{i}^{*} \frac{1}{N}
$$




$$
\frac{\partial \pi_{i}}{\partial N}=-\frac{1}{N^{2}}\left(A-w_{i}^{*}\right) w_{i}^{*}+\frac{1}{N} \frac{\partial w_{i}^{*}}{\partial N}\left(A-2 w_{i}^{*}\right) \lesseqgtr 0 \text { with } \widehat{w}_{i}<w_{i}^{*} \text { and } \frac{\partial w_{i}^{*}}{\partial N}<0(60)
$$

Let us illustrate this case with a numerical example. We assume that $A=10$ and $t=300$. The first derivative of a channel's profit function with respect to $\mathrm{N}$ is zero at the values $N_{1} \approx 25.597$ and $N_{2} \approx 40.838$. Therefore, we have two extrema. Checking the second order condition yields

$$
\begin{aligned}
& \frac{\partial^{2} \pi_{i}}{\partial N^{2}}=0.002224>0 \text { with } N_{1}=25.597 \\
& \frac{\partial^{2} \pi_{i}}{\partial N^{2}}=-0.0010858<0 \text { with } N_{2}=40.838 .
\end{aligned}
$$

Hence, the profit of a channel is increasing in $N$ for $N \in] N_{1} ; N_{2}[$. Figure 2 shows a channel's advertising level and a channel's profit for the numerical example. We see that the profit starts to decrease in $N$, then it increases in $N$, and if $N>41$, then it decreases again.

Situation 4. $\widehat{w}_{i}>w_{i}^{*}$ and $\frac{\partial w_{i}^{*}}{\partial N}>0$

Theoretically, this situation may be possible. It could be that the equilibrium advertising level is too low and that market entry leads to a higher equilibrium advertising level. Nevertheless, we can exclude this case with our chosen functions. Given that the differentiation parameter $t$ is above the threshold level, the advertising level is always higher than $\widehat{w}_{i}$ with $N>2$.

To show this we calculate the smallest possible $w_{i}^{*}$ given $t \geq \frac{2 N^{2} A}{2+N}$ and compare it to $\hat{w}$

$$
w_{i}^{*}\left(t=\frac{2 N^{2} A}{2+N}\right)=\frac{N A}{2+N}>\frac{A}{2} \forall N>2 .
$$

We summarize our findings in the following proposition.

Proposition 5. Market entry decreases the profits of the incumbents

- if the differentiation is relatively high $\left(t>\frac{2 N^{2} A}{2+N}\right)$. The equilibrium advertising level is above the revenue maximizing advertising level and market entry increases the equilibrium advertising level. 


\section{Advertising Level and Profit}

Numerical example: $A=10 ; t=300$

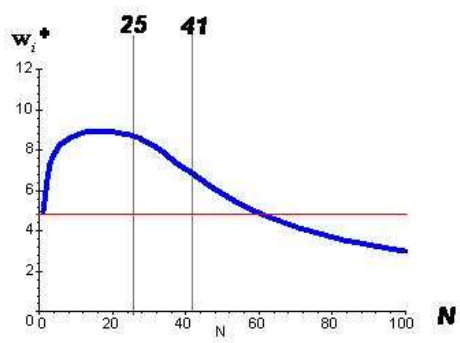

Equilibrium advertising level

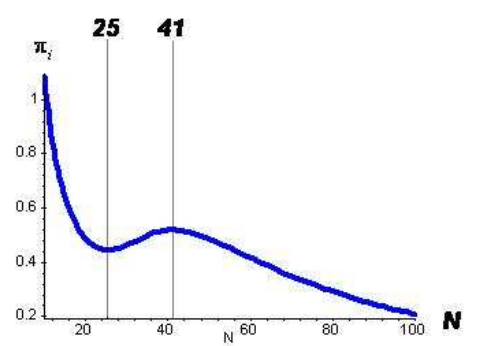

Profit

Richard Schmidtke

Figure 2: Advertising level and profit

- if the differentiation is relatively low $\left(t<\frac{N^{2} A}{2 N-2}\right)$. The equilibrium advertising level is below the revenue maximizing advertising level and market entry decreases the equilibrium advertising level.

If the differentiation parameter has a medium value $\left(\frac{2 N^{2} A}{2+N}>t>\frac{N^{2} A}{2 N-2}\right)$, then the equilibrium advertising level is above the revenue maximizing advertising level. Furthermore, market entry leads to a lower equilibrium advertising level. In this case it might occur that the incumbents' profits increase with market entry.

Proof. We know that $\widehat{w}_{i}=\frac{A}{2}$. Looking for $t$ s.t. $w_{i}^{*}=\frac{A}{2}$ yields

$$
t=\frac{N^{2} A}{2 N-2}
$$

For the rest see above. 
The surprising finding that market entry can lead to higher profits comes from the two externalities that are incorporated in our model. Given the pecuniary externality, a platform does not internalize that it decreases the other platforms' profits if he increases the supply of viewer-time units. This goes in the direction of a too high advertising level compared to the collusive advertising level. Hence, the platforms would like to commit to a lower advertising level. Therefore, individually rational behavior leads to a too high advertising level compared to collectively rational behavior.

On the other hand, we have the participation externality. Given this externality, a platform does not internalize that it increases the profits of the competing platforms if he chooses a higher advertising level. This goes in the direction of a too low advertising level. Hence, the platforms would like to commit to a higher advertising level. Therefore, individually rational behavior leads to a too low advertising level compared to collectively rational behavior.

To illustrate this point, consider the example of two channels and the parameter values $A=100$ and $t=200$. Although we have competition, the equilibrium advertising level $w_{i}^{*}=50$ equals the collusive advertising level $\hat{w}_{i}=50$. We see that the "suboptimal" behavior of the firms on one side of the market, from a collusive point of view, corrects the "suboptimal" behavior on the other side of the market. ${ }^{14}$

In the following we consider the impact of market entry on social welfare. A social planer, who wants to determine the optimal advertising level $\widetilde{w}$, has to solve the following trade-off. On the one hand, a higher advertising level increases the surplus of the advertisers. On the other hand, a higher advertising level decreases the surplus of the viewers. One can easily determine the optimal advertising level that solves this trade-off. The willingness to pay of the advertisers $(p)$ should be

\footnotetext{
${ }^{14}$ Reisinger (2004) shows a related effect of the interaction between the two markets. In his paper he considers a situation where two platforms compete in prices and the advertisers total demand is fixed. Suppose that the differentiation parameter is very high. Hence, viewers never switch between the platforms. Competition between the channels yields an advertising price of zero. In such a situation Reisinger (2004) shows that an exogenous decrease of the differentiation parameter increases the profits. The intuition is that viewers begin to switch. Therefore, the channels have to take care of their advertising levels. This leads to higher prices for advertising, which yields a higher profit per channel.
} 
equal to the marginal change in the viewers' utility $(=1)$.

$$
\begin{aligned}
& 1=A-\widetilde{w} \\
& \widetilde{w}=A-1
\end{aligned}
$$

One can compute the necessary relationship between $t, A$ and $N$ such that the equilibrium advertising level is equal to the social optimal advertising level $\widetilde{w}_{i}$

$$
\begin{aligned}
& \widetilde{w}_{i}=\frac{N t+t+N^{2} A-\sqrt{\left(N t+t+N^{2} A\right)^{2}-4 N^{3} t A}}{2 N^{2}}=A-1 ; \\
& t=N^{2} \frac{A-1}{N+1-A} .
\end{aligned}
$$

Concerning the effects of market entry on the social welfare, we have to take into account the reduction of the consumers' transportation costs. Hence, the social welfare function is

$$
W F=(A-w) w+\frac{1}{2} w^{2}-\frac{t}{4 N}-w .
$$

In order to consider whether market entry leads to a higher or lower welfare, we have again to distinguish between four situations:

Situation 1: $w_{i}^{*}>\widetilde{w}_{i}$ and $\frac{\partial w_{i}^{*}}{\partial N}<0 \rightarrow \frac{\partial W F}{\partial N}>0$

In this first case the differentiation parameter $t$ is between $\frac{2 N^{2} A}{2+N}>t>$ $N^{2} \frac{A-1}{N+1-A}$. Hence, the advertising level is too high from a welfare point of view. Market entry leads to a lower advertising level because the transportation costs are below the threshold level. In this case market entry unambiguously increases welfare. The advertising level moves in the right direction and the consumers' transportation costs decrease. Given that the differentiation parameter $t$ can be in the mentioned area, the parameter $A$ has to be $A>1+\frac{N}{2} \cdot 15$

$$
15 \frac{2 N^{2} A}{2+N}>N^{2} \frac{A-1}{N+1-A} \rightarrow A>1+\frac{N}{2}
$$


Situation 2: $w^{*}<\widetilde{w}$ and $\frac{\partial w^{*}}{\partial N}>0 \rightarrow \frac{\partial W F}{\partial N}>0$

As in case 1, in this second case market entry increases the social welfare. If $A>1+\frac{N}{2}$ then $t$ can be between $N^{2} \frac{A-1}{N+1-A}>t>\frac{2 N^{2} A}{2+N}$. Hence, the advertising level is below the social optimal advertising level. Market entry increases the advertising level. Furthermore, the viewers' transportation costs decrease if market entry occurs.

Situation 3: $w^{*}>\widetilde{w}$ and $\frac{\partial w^{*}}{\partial N}>0 \rightarrow \frac{\partial W F}{\partial N} \lesseqgtr 0$

If $t$ is very high $\left(t>\max \left\{N^{2} \frac{A-1}{N+1-A}, \frac{2 N^{2} A}{2+N}\right\}\right)$, then the equilibrium advertising level is above the social optimal level. Market entry yields two counteracting effects. On the one hand, the consumers' transportation costs are reduced. On the other hand, the advertising level moves in the "wrong" direction. Nevertheless, numerical examples let us expect that the positive effect on social welfare always dominates.

Situation $4: w^{*}<\widetilde{w}$ and $\frac{\partial w^{*}}{\partial N}<0 \rightarrow \frac{\partial W F}{\partial N} \lesseqgtr 0$

If the differentiation parameter $t$ is very low $\left(t<\min \left\{N^{2} \frac{A-1}{N+1-A}, \frac{2 N^{2} A}{2+N}\right\}\right)$, then the advertising level is above the social optimal level. Market entry decreases the advertising level even further. Even if the consumers' transportation costs are reduced, it can happen that the social welfare decreases with market entry. In particular this is true when $N$ goes to infinity and $A$ above the critical value $\frac{5}{4}$. Given a high $N$ and further market entry, the decrease of the transportation costs is negligibly and the negative effect of a lower advertising level dominates. Therefore, we conclude that perfect competition has not to be desirable from a welfare point of view.

Proposition 6. The equilibrium advertising level can be above or below the social optimal advertising level. Therefore, market entry has two welfare effects. On the one hand, it changes the equilibrium advertising level. This can increase or decrease social welfare. On the other hand, it decreases the transportation costs of the viewers, which unambiguously increases welfare. In particular if $A>\frac{5}{4}$, then perfect competition does not maximize social welfare. 
Proof. See Appendix.

\section{Conclusion}

In this paper we have analyzed a two-sided market model where broadcasting channels offer a costless program to viewers. The channels make profits by selling viewer-time units to advertisers. In contrast to the existing literature, we have combined the "participation externality" (more advertisements on platform $i$ decrease its own audience size and increase the other platforms' audience sizes) and the "pecuniary externality" (more advertisements on platform $i$ changes the advertisers' willingness to pay on all platforms). We have given two examples: the "Code of Conduct" of the National Association of Broadcasters in the US and the discussion about advertising on public broadcasting channels in Germany. Both examples illustrate the existence of pecuniary externalities. We have provided two microfoundations for pecuniary externalities, namely a convex cost function and word-of-mouth advertising. We have shown that advertising can have the property of a strategic substitute or complement. Furthermore, market entry can increase or decrease the equilibrium advertising level. Both is in contrast to the existing literature. Moreover, we have shown that market entry can make incumbents better off and that perfect competition does not have to be desirable from a welfare point of view.

Given the introduction of Digital Television, our model leads to the policy implication that governments should be careful with additional broadcasting licenses. In particular they should take into account that the equilibrium advertising level can move in the wrong direction and that this can decrease welfare. Furthermore, our model shows that advertising ceilings, which restrict the time that a channel can offer to advertisers, can be used as a collusive device between the broadcasting channels in order to increase the price for advertising. This function of advertising ceilings does not appear in the existing literature. Therefore, we conclude that a government should be careful with such advertising ceilings, particularly if the channels ask for such ceilings in order to protect viewer against "too much" advertising. 
Natural extensions of this model would be to consider the program quality choices of the broadcasters and to consider the introduction of subscription fees. In particular the last point seems quite interesting. The existing literature, like Peitz and Valetti (2004), only considers subscription fees in the Anderson and Coate (2005) framework, so without pecuniary externalities. It would be interesting to analyze subscription fees under perfect competition in a model that includes pecuniary externalities. Without pecuniary externalities, channels set monopoly advertising levels and compensate the viewers by a corresponding lower subscription price. Hence, an inefficiency arises due to the monopoly advertising level, which is persistent even under perfect competition. Given pecuniary externalities, perfect competition would drive the advertising level to the social optimal level. Therefore, with two instruments, advertising prices and subscription prices, and two externalities, pecuniary and participation externalities, more competition would always increase social welfare. Hence, perfect competition would be unambiguously desirable from a welfare point of view. 


\section{Appendix}

\section{Switching Viewers}

We consider "switching viewers" in order to derive pecuniary externalities. As in Anderson and Coate (2005), we consider two periods (say day 1 and day 2) where the channels broadcast their programs and viewers watch these programs. Assume furthermore that the channels have to commit to their advertising levels for the two periods in advance. Additionally, we make the assumption that the viewers reallocate after the day 1 on the Salop circle at random. A possible explanation is that the kind of differentiation of the channels is different. For an illustration assume that channel $A$ broadcasts always US movies and channel $B$ broadcasts always French movies. If a viewer decides to watch the US movie, then this has not to imply that this viewer always watches this channel. Perhaps he has chosen the US movie because it was a black and white movie and next time the French movie is black and white. Or he preferred the US movie because it was a love story and next time the French channel has the better love story to offer.

Let us look at a representative advertiser $g$. If he advertises $w_{g i 1}$ on channel $i$ in the first period, then the viewers of this channel buy his product with a probability of $z=z\left(w_{g i 1}\right)$. We assume that the probability function $z$ is concave in the advertising level

$$
z^{\prime}>0, z^{\prime \prime}<0 \text { with } z(0)=0, z(\infty)=1 .
$$

This assumption ensures that the second order condition of the advertisers are globally satisfied. We stick to the assumption that each consumer is only interested in one unit of a certain product. This implies that all viewers who have bought a product in the first period will for sure not buy such a product in the second period. Hence, only a non-buyer of the first period can get informed about the product of advertiser $g$ in the second period. In this second period the probability $z$ depends again on the length of the advertising spot.

This leads to the following expected profit function for advertiser $g$ :

$$
\pi_{g}=v\left[\sum_{j=1}^{N} D_{j 1}\left(z\left(w_{g j 1}\right)+\left(1-z\left(w_{g j 1}\right)\right) \sum_{i=1}^{N} D_{i 2} z\left(w_{g i 2}\right)\right]-\sum_{j=1}^{N} p_{j 1} w_{g j 1} D_{j 1}-\sum_{i=1}^{N} p_{i 2} w_{g i 2} D_{i 2} .\right.
$$


Maximizing with respect to the optimal advertising level on channel $\mathrm{k}$ in both periods leads to

$$
\begin{aligned}
& p_{k 1}=v\left[1-\sum_{i=1}^{N} D_{i 2} z\left(w_{g i 2}\right)\right] z^{\prime}\left(w_{g k 1}\right) \\
& p_{k 2}=v\left[1-\sum_{j=1}^{N} D_{j 1} z\left(w_{g j 1}\right)\right] z^{\prime}\left(w_{g k 2}\right)
\end{aligned}
$$

For simplicity let us assume, as Anderson and Coate (2005), that every channel offers the same time for commercials in both periods. ${ }^{16}$ This implies that given $w_{i}$, a channel $i$ has the audience size $D_{i}$ in both periods. In particular the channel $k$ gets the same per viewer-time unit time price $p_{k}$ in both periods. This price $p_{k}$ is

$$
p_{k}=p_{k 1}=p_{k 2}=v\left[1-\sum_{j=1}^{N} D_{j} z\left(w_{g j}\right)\right] z^{\prime}\left(w_{g k}\right) .
$$

If another channel $l$ changes its advertising level in such a way that firm $g$ advertises more on this channel, then it distorts the price $p_{k}$

$$
\frac{\partial p_{k}}{\partial w_{g} l}=-v D_{l} z^{\prime}\left(w_{g l}\right) z^{\prime}\left(w_{g k}\right)<0 .
$$

Thus, the broadcasting channels have pecuniary externalities. The intuition for this is straightforward: if an advertiser advertises more on channel $l$ in both periods, then this leads to a decrease in the effectiveness of advertising on channel $k$. The reason is simply that the probability to get a non-buyer gets smaller (through the higher advertising level on channel $l$ ) and therefore the net payoff from advertising decreases.

\section{Proof of Proposition 1}

Symmetry and the knowledge $D_{i}=\frac{1}{N}$ yields:

$$
\frac{\partial \pi_{i}}{\partial w_{i}}=-\frac{1}{t} w_{i}\left[A-N w_{i} \frac{1}{N}\right]+\frac{1}{N}\left[A-N w_{i} \frac{1}{N}\right]-\frac{1}{N^{2}} w_{i}=0
$$

\footnotetext{
${ }^{16}$ Given the assumption, the channels have pecuniary externalities on each other in both periods. If we allow for different advertising levels in the two periods, then we derive intertemporal externalities in the sense that the advertising level of channel $l$ in one period influences the willingness to pay of the advertiser in the other period. Such a dynamic analysis is beyond the scope of this paper. But we expect that such a dynamic model yields qualitatively the same results.
} 


$$
\begin{gathered}
\frac{\partial \pi_{i}}{\partial w_{i}}=-\frac{1}{t} w_{i} A+\frac{1}{t} w_{i}^{2}+\frac{1}{N} A-\frac{1}{N} w_{i}-\frac{1}{N^{2}} w_{i}=0 \\
\frac{\partial \pi_{A}}{\partial w_{A}}=-N^{2} w_{i} A+N^{2} w_{i}^{2}+N t A-N t w_{i}-t w_{i}=0 \\
\frac{\partial \pi_{A}}{\partial w_{A}}=N^{2} w_{i}^{2}+\left[-N t-t-N^{2} A\right] w_{i}+N t A=0 \\
w_{i_{1,2}}=\frac{\left(N t+t+N^{2} A\right) \pm \sqrt{\left(N t+t+N^{2} A\right)^{2}-4 N^{3} t A}}{2 N^{2}}
\end{gathered}
$$

Checking the second-order condition:

$$
\frac{\partial^{2} \pi_{i}}{\partial w_{i}^{2}}=\frac{\partial^{2} D_{i}}{\partial w_{i}^{2}} w_{i} p+2 \frac{\partial D_{i}}{\partial w_{i}} p+2 \frac{\partial D_{i}}{\partial w_{i}} w_{i} \frac{d p}{d w_{i}}+2 D \frac{d p}{d w_{i}}+2 D_{i} w_{i} \frac{d^{2} p}{d w_{i}^{2}}<0
$$

Evaluating at a symmetric equilibrium yields:

$$
\begin{gathered}
-\frac{1}{t} p^{*}+2 \frac{1}{t} w_{i}^{*} \frac{1}{N}-\frac{1}{N^{2}}<0 \\
p>2 w_{i}^{*} \frac{1}{N}-\frac{t}{N^{2}} \\
A-w_{i}^{*}>2 w_{i}^{*} \frac{1}{N}-\frac{t}{N^{2}} \\
w_{i}<\frac{t+A N^{2}}{N^{2}+2 N}
\end{gathered}
$$

Now plugging in

$$
w_{i}^{*}=\frac{\left(N t+t+N^{2} A\right)-\sqrt{\left(N t+t+N^{2} A\right)^{2}-4 N^{3} t A}}{2 N^{2}}
$$

This gives

$$
\begin{gathered}
\frac{\left(N t+t+N^{2} A\right)-\sqrt{\left(N t+t+N^{2} A\right)^{2}-4 N^{3} t A}}{2 N^{2}}<\frac{t+A N^{2}}{N^{2}+2 N} \\
\frac{\left(N t+t+N^{2} A\right)-\sqrt{\left(N t+t+N^{2} A\right)^{2}-4 N^{3} t A}}{2 N^{2}}-\frac{t+A N^{2}}{N^{2}+2 N}<0 \\
N^{2} t+N t+2 t-N^{3} A+2 N^{2} A-(N+2) \sqrt{\left(N t+t+N^{2} A\right)^{2}-4 N^{3} t A}<0
\end{gathered}
$$

Case 1: If $N^{2} t+N t+2 t-N^{3} A+2 N^{2} A \leq 0$, then SOC is fulfilled. 
Case 2: If $N^{2} t+N t+2 t-N^{3} A+2 N^{2} A>0$, then we have to show that

$$
\begin{gathered}
N^{2} t+N t+2 t-N^{3} A+2 N^{2} A<(N+2) \sqrt{\left(N^{2} t^{2}+2 N t^{2}-2 N^{3} t A+t^{2}+2 t N^{2} A+N^{4} A^{2}\right)} \\
\left(N^{2} t+N t+2 t-N^{3} A+2 N^{2} A\right)^{2}<(N+2)^{2}\left(N^{2} t^{2}+2 N t^{2}-2 N^{3} t A+t^{2}+2 t N^{2} A+N^{4} A^{2}\right) \\
-8 N^{2} t^{2}-8 N t^{2}-8 N^{5} A^{2}-4 N^{3} t^{2}+8 N^{4} t A<0 \\
2 N t^{2}+2 t^{2}+2 N^{4} A^{2}+N^{2} t^{2}-2 N^{3} t A>0
\end{gathered}
$$

We know that the term $2 N t^{2}+2 t^{2}+2 N^{4} A^{2}+N^{2} t^{2}-2 N^{3} t A$ is always positive or negative because the Determinant with respect to $t$ and $A$ is negative. We see immediately that the term is positive for $N=1\left(2 t^{2}+2 t^{2}+2 A^{2}+t^{2}-2 t A=\right.$ $\left.4 t^{2}+A^{2}+(A-t)^{2}>0\right)$. Furthermore, we can show that the term $2 N t^{2}+2 t^{2}+$ $2 N^{4} A^{2}+N^{2} t^{2}-2 N^{3} t A$ is increasing in $N$. Therefore it is positive for all $N>1$.

$$
\begin{gathered}
\left.\frac{\partial\left(2 N t^{2}+2 t^{2}+2 N^{4} A^{2}+\right.}{\partial N} N^{2} t^{2}-2 N^{3} t A\right) \\
8 N^{3} A^{2}+2 N t^{2}-6 t N^{2} A>0 \\
4 N^{3} A^{2}+N t^{2}-3 t N^{2} A>0 \\
4 N^{2} A^{2}+t^{2}-3 t N A>0 \\
(2 N A-t)^{2}+N A t>0
\end{gathered}
$$

Now showing that

$$
w=\frac{\left(N t+t+N^{2} A\right)+\sqrt{\left(N t+t+N^{2} A\right)^{2}-4 N^{3} t A}}{2 N^{2}}
$$

is a minimum.

Plugging into

$$
w_{i}^{*}<\frac{t+A N^{2}}{N^{2}+2 N}
$$

yields

$$
N^{2} t+N t+2 t-N^{3} A+2 N^{2} A+(N+2) \sqrt{\left(N t+t+N^{2} A\right)^{2}-4 N^{3} t A}>0
$$

Case 1: If $N^{2} t+N t+2 t-N^{3} A+2 N^{2} A>0$, then SOC is not fulfilled. 
Case 2: If $N^{2} t+N t+2 t-N^{3} A+2 N^{2} A \leq 0$, then we have to show

$$
\left(N^{2} t+N t+2 t-N^{3} A+2 N^{2} A\right)^{2}<(N+2)^{2}\left(\left(N t+t+N^{2} A\right)^{2}-4 N^{3} t A\right) .
$$

We know that this is true. See proof of maximum.

\section{Proof of Proposition 2}

For Case 2:

$$
\begin{gathered}
\left.\frac{\partial \pi_{i}}{d w_{i}}\right|_{w_{i}=w_{-i}-\frac{t}{2}}=\frac{1}{2 t}\left(-7 w_{-i} t+3 t^{2}+2 w_{-i}^{2}+3 A t-2 A w_{-i}\right)=0 \\
\rightarrow w_{-i}=\frac{7}{4} t+\frac{1}{2} A \pm \frac{1}{4} \sqrt{\left(25 t^{2}+4 A t+4 A^{2}\right)}
\end{gathered}
$$

Hence, if player $i$ plays $w_{i}=w_{-i}-\frac{t}{2}$, then the FOC has two nulls. We can exclude the point $w_{-i}=\frac{7}{4} t+\frac{1}{2} A+\frac{1}{4} \sqrt{\left(25 t^{2}+4 A t+4 A^{2}\right)}$ because

$$
w_{-i}=\frac{7}{4} t+\frac{1}{2} A+\frac{1}{4} \sqrt{\left(25 t^{2}+4 A t+4 A^{2}\right)}>w_{-i}^{H}=\frac{A}{2}-\frac{t}{2}
$$

and therefore it falls in the range of Case 1.

Now we check if $w_{i}=\frac{7}{4} t+\frac{1}{2} A-\frac{1}{4} \sqrt{\left(25 t^{2}+4 A t+4 A^{2}\right)}-\frac{t}{2}$ is indeed a maximum given $w_{-i}=\frac{7}{4} t+\frac{1}{2} A-\frac{1}{4} \sqrt{\left(25 t^{2}+4 A t+4 A^{2}\right)}$. Checking the SOC at the value $w_{i}=$ $\frac{7}{4} t+\frac{1}{2} A-\frac{1}{4} \sqrt{\left(25 t^{2}+4 A t+4 A^{2}\right)}-\frac{t}{2}$ and $w_{-i}=\frac{7}{4} t+\frac{1}{2} A-\frac{1}{4} \sqrt{\left(25 t^{2}+4 A t+4 A^{2}\right)}$ yields

$$
\frac{\partial^{2} \pi_{i}}{\partial w_{i}^{2}}=\frac{1}{4 t}\left(6 A+23 t-7 \sqrt{\left(25 t^{2}+4 A t+4 A^{2}\right)}\right) .
$$

To show $\frac{1}{4 t}\left(6 A+23 t-7 \sqrt{\left(25 t^{2}+4 A t+4 A^{2}\right)}\right)<0$. Simplifying yields

$$
-160 A^{2}+80 A t-696 t^{2}<-\left(\frac{1}{2} A\right)^{2}+A t-t^{2}=-\left(\frac{1}{2} A-t\right)^{2}<0
$$

Now more generally: Given the nulls at $w_{-i}=\frac{7}{4} t+\frac{1}{2} A \pm \frac{1}{4} \sqrt{\left(25 t^{2}+4 A t+4 A^{2}\right)}$ for $w_{i}=w_{-i}-\frac{t}{2}$ and the fact that the SOC is negative at the point $w_{i}=w_{-i}-\frac{t}{2}$ with $w_{-i}=\frac{7}{4} t+\frac{1}{2} A-\frac{1}{4} \sqrt{\left(25 t^{2}+4 A t+4 A^{2}\right)}$ we have that the FOC is negative for all $w_{i}=w_{-i}-\frac{t}{2}$ with

$$
\left.w_{-i} \in\right] \frac{7}{4} t+\frac{1}{2} A-\frac{1}{4} \sqrt{\left(25 t^{2}+4 A t+4 A^{2}\right)} ; \frac{7}{4} t+\frac{1}{2} A+\frac{1}{4} \sqrt{\left(25 t^{2}+4 A t+4 A^{2}\right)}[
$$

- Therefore, it would payoff to decrease $w_{i}$. But we are at a kink of the profit function. Hence, $w_{i}=w_{-i}-\frac{t}{2}$ is indeed a maximum. Further decreasing $w_{i}$ does 
not change the audience size (it is $D_{i}=1$ ), but reduces the revenue per viewer. Next, we show that

$$
\begin{gathered}
\frac{7}{4} t+\frac{1}{2} A-\frac{1}{4} \sqrt{\left(25 t^{2}+4 A t+4 A^{2}\right)}<\frac{A}{2}+\frac{t}{2} \\
\frac{7}{4} t+\frac{A}{2}-\frac{1}{4} \sqrt{25 t^{2}+4 A t+4 A^{2}}-\left(\frac{A}{2}+\frac{t}{2}\right)<0 \\
\frac{5}{4} t-\frac{1}{4} \sqrt{\left(25 t^{2}+4 A t+4 A^{2}\right)}<0 \\
\frac{5}{4} t<\frac{1}{4} \sqrt{\left(25 t^{2}+4 A t+4 A^{2}\right)}
\end{gathered}
$$

This is true for all $t>0$ and $A>0$.

For Case 3:

We have to show that the value $w_{i}^{\text {Case } 3}$ is indeed an optimum. Therefore, we show that for all values of $w_{i}$ s.t. $w_{-i}-\frac{t}{2} \leq w_{i} \leq w_{-i}+\frac{t}{2}$ the second order condition is fulfilled given that $w_{-i}<\frac{7}{4} t+\frac{1}{2} A-\frac{1}{4} \sqrt{\left(25 t^{2}+4 A t+4 A^{2}\right)}$.

$$
\frac{\partial^{2} \pi_{i}}{\partial w_{i}^{2}}=-\frac{1}{2} \frac{4 A t-12 w_{i} t+24 w_{i}^{2}-36 w_{i} w_{-i}+4 w_{-i} t+12 w_{-i}^{2}+t^{2}}{t^{2}}
$$

Given $w_{i}=w_{i}+x$ with $-\frac{t}{2} \leq x \leq \frac{t}{2}, \frac{\partial^{2} \pi_{i}}{\partial w_{i}^{2}}<0$ if

$$
4 A t-8 w_{-i} t-12 t x+12 w_{-i} x+24 x^{2}+t^{2}>0
$$

This term is decreasing in $w_{i}$ due to $-\frac{t}{2} \leq x \leq \frac{t}{2}$. The term is zero if

$$
w_{-i}^{z e r o}=\frac{4 A t-12 t x+24 x^{2}+t^{2}}{8 t-12 x}
$$

Hence, it is sufficient to show that $w_{-i}^{z e r o}>w_{-i}^{C}$

$$
\begin{gathered}
w_{-i}^{z e r o}>\frac{4 A t-12 t * 0+24 * 0^{2}+t^{2}}{8 t-12\left(-\frac{t}{2}\right)}>w_{-i}^{C} \\
\frac{2}{7} A+\frac{1}{14} t>\frac{7}{4} t+\frac{1}{2} A-\sqrt{25 t^{2}+4 A t+4 A^{2}} \\
\frac{3}{14} A+\frac{47}{28} t<\sqrt{25 t^{2}+4 A t+4 A^{2}} \\
\frac{9}{196} A^{2}+\frac{141}{196} A t+\frac{2209}{784} t^{2}-\left(25 t^{2}+4 A t+4 A^{2}\right)=-\frac{775}{196} A^{2}-\frac{643}{196} A t-\frac{17391}{784} t^{2}<0
\end{gathered}
$$




\section{Proof of Proposition 3}

With $w_{A}=w_{B}=w_{i}$ it follows:

$$
\frac{\partial^{2} \pi}{\partial w_{A} \partial w_{B}}=\frac{A-w_{i}}{t}-\frac{1}{4}-\frac{w_{i}}{t}
$$

Strategic substitutes:

$$
\begin{gathered}
w_{i}^{*}=\frac{3}{8} t+\frac{1}{2} A-\frac{1}{8} \sqrt{9 t^{2}-8 A t+16 A^{2}} i \in\{A, B\} \\
\frac{\partial^{2} \pi}{\partial w_{A} \partial w_{B}}=-1+\frac{1}{4 t} \sqrt{\left(9 t^{2}-8 A t+16 A^{2}\right)}<0 \\
\frac{1}{4 t} \sqrt{\left(9 t^{2}-8 A t+16 A^{2}\right)}<1 \\
\frac{1}{16 t^{2}}\left(9 t^{2}-8 A t+16 A^{2}\right)<1 \\
9 t^{2}-8 A t+16 A^{2}<16 t^{2} \\
-7 t^{2}-8 A t+16 A^{2}<0 \\
\frac{d\left(-7 t^{2}-8 A t+16 A^{2}\right)}{d t}=-14 t-8 A<0 \\
-7 t^{2}-8 A t+16 A^{2}=0 \\
t_{1}=-\frac{4}{7} A-\frac{8}{7} \sqrt{2} A<0 \\
t_{2}=-\frac{4}{7} A+\frac{8}{7} \sqrt{2} A>0
\end{gathered}
$$

Therefore given $A$, the function is positive for all $t \in] t_{1} ; t_{2}[$. Hence, we have strategic substitutes if

$$
t>-\frac{4}{7} A+\frac{8}{7} \sqrt{2} A=\frac{4}{7} A(2 \sqrt{2}-1)
$$

Otherwise we have strategic complements.

\section{Proof of Lemma 1}

We show $\frac{\partial w_{i}^{*}}{\partial t}>0$ by using the implicit function theorem.

$$
\left.d \frac{\partial \pi_{i}}{\partial w_{i}}\right|_{w_{1}^{*}=\ldots=w_{N}^{*}}=\frac{\partial \frac{\partial \pi_{i}}{\partial w_{i}}}{\partial t} d t+\frac{\partial^{2} \pi_{i}}{\partial w_{i}^{2}} d w_{i}=0
$$




$$
\begin{aligned}
\frac{d w_{i}^{*}}{d t} & =-\frac{p w_{i}^{*} \frac{\partial D_{i}}{\partial w_{i} \partial t}}{[S O C]} \\
\frac{d w_{i}^{*}}{d t} & =-\frac{p w_{i}^{*} \frac{1}{t^{2}}}{[S O C]}>0
\end{aligned}
$$

We show $\frac{\partial w_{i}^{*}}{\partial A}>0$ by using the implicit function theorem.

$$
\begin{gathered}
\left.d \frac{\partial \pi_{i}}{\partial w_{i}}\right|_{w_{1}^{*}=\ldots=w_{N}^{*}}=\frac{\partial \frac{\partial \pi_{i}}{\partial w_{i}} d+A \frac{\partial^{2} \pi_{i}}{\partial w_{i}^{2}} d w_{i}=0}{\frac{d w_{i}^{*}}{d A}=-\frac{p w_{i}^{*} \frac{\partial D_{i}}{\partial w_{i} \partial A}}{[S O C]}} \\
\frac{d w_{i}^{*}}{d A}=-\frac{-\frac{1}{t} \frac{\partial p}{\partial A} w_{i}^{*}+\frac{1}{N} \frac{\partial p}{\partial A}}{[S O C]} \\
\frac{d w_{i}^{*}}{d A}=-\frac{\frac{\partial p}{\partial A} \frac{\partial\left(D_{i} w_{i}\right)}{\partial w_{i}}}{[S O C]}>0
\end{gathered}
$$

because

$$
\left.\frac{\partial \pi_{i}}{\partial w_{i}}\right|_{w_{1}^{*}=\ldots=w_{N}^{*}}=\overbrace{p \frac{\partial\left(D_{i} w_{i}\right)}{\partial w_{i}}}^{+}+\overbrace{\frac{\partial p}{\partial w_{i}} D_{i} w_{i}}^{-}=0
$$

\section{Proof of Proposition 4}

The first order condition at a symmetric equilibrium $w_{1}^{*}=\ldots=w_{N}^{*}$ is

$$
\frac{\partial \pi_{i}}{\partial w_{i}}=-\frac{1}{t} p w_{i}^{*}+\frac{1}{N} \frac{\partial\left(w_{i}^{*} p\right)}{\partial w_{i}}=0
$$

By totally differentiating this first order condition we get

$$
\begin{gathered}
{[S O C] d w_{i}+\left[-\frac{1}{t} \frac{\partial\left(w_{i}^{*} p\right)}{\partial N}-\frac{1}{N^{2}} \frac{\partial\left(w_{i}^{*} p\right)}{\partial w_{i}}+\frac{1}{N} \frac{\partial \frac{\partial\left(p w_{i}^{*}\right)}{\partial w_{i}}}{\partial N}\right] d N=0} \\
{[S O C] d w_{i}+\left[-\frac{1}{N^{2}} \frac{\partial\left(w_{i}^{*} p\right)}{\partial w_{i}}+\frac{1}{N} \frac{\partial \frac{\partial\left(p w_{i}^{*}\right)}{\partial w_{i}}}{\partial N}\right] d N=0} \\
\frac{\partial w_{i}^{*}(N)}{\partial N}=-\frac{-\frac{1}{N^{2}} \frac{\partial\left(w_{i}^{*} p\right)}{\partial w_{i}}+\frac{1}{N} \frac{\partial \frac{\partial\left(p w_{i}^{*}\right)}{\partial w_{i}}}{[S O C]}}{[S O}
\end{gathered}
$$


Therefore, $\frac{\partial w_{i}^{*}(N)}{\partial N}>0$ if

$$
\begin{gathered}
-\frac{1}{N^{2}} \frac{\partial\left(w_{i}^{*} p\right)}{\partial w_{i}}+\frac{1}{N} \frac{\partial \frac{\partial\left(p w_{i}^{*}\right)}{\partial w_{i}}}{\partial N}>0 \\
\frac{\partial \frac{\partial\left(p w_{i}^{*}\right)}{\partial w_{i}}}{\partial N}>\frac{1}{N} \frac{\partial\left(w_{i}^{*} p\right)}{\partial w_{i}} \\
\frac{\partial\left(p-\frac{1}{N} w_{i}^{*}\right)}{\partial N}>\frac{1}{N}\left(p-\frac{1}{N} w_{i}^{*}\right) \\
\frac{1}{N^{2}} w_{i}^{*}>\frac{1}{N}\left(p-\frac{1}{N} w_{i}^{*}\right) \\
\frac{2}{N} w_{i}^{*}>p \\
w_{i}^{*}>\left(A-w^{*}\right) \\
>\frac{A N}{2+N}
\end{gathered}
$$

Plugging in $w_{i}^{*}$, one sees that this is the case if $t>\frac{2 N^{2} A}{2+N}$

\section{Proof of Proposition 6}

It remains to show:

$$
\lim _{N \rightarrow \infty}\left(\frac{\partial W F}{\partial N}=\frac{\partial w_{i}^{*}}{\partial N}\left(A-w_{i}^{*}-1\right)+\frac{t}{4 N^{2}} \leq 0\right)
$$

Using the Implicit Function Theorem we know that

$$
\frac{\partial w_{i}^{*}}{\partial N}=-\frac{\frac{1}{N^{2}}\left(\frac{N+2}{N} w_{i}^{*}-A\right)}{-\frac{A}{t}+\frac{N+2}{N t} w_{i}^{*}-\frac{1}{N^{2}}}
$$

This leads to

$$
\begin{gathered}
\frac{\partial W F}{\partial N}=-\frac{\frac{1}{N^{2}}\left(\frac{N+2}{N} w_{i}^{*}-A\right)}{-\frac{A}{t}+\frac{N+2}{N t} w_{i}^{*}-\frac{1}{N^{2}}}\left(A-w_{i}^{*}-1\right)+\frac{t}{4 N^{2}} \\
\lim _{N \rightarrow \infty} \frac{1}{N^{2}}\left\{\frac{-\left(\frac{N+2}{N} w_{i}^{*}-A\right)}{-\frac{A}{t}+\frac{N+2}{N t} w_{i}^{*}-\frac{1}{N^{2}}}\left(A-w_{i}^{*}-1\right)-\frac{t}{4}\right\}=0
\end{gathered}
$$


due to

$$
\lim _{N \rightarrow \infty} w_{i}^{*}=\frac{\left(\frac{t}{N}+\frac{t}{N^{2}}+A\right)-\frac{\sqrt{\left(N t+t+N^{2} A\right)^{2}-4 N^{3} t A}}{N^{2}}}{2}=0
$$

Now to show that we approach zero from below with $A>\frac{5}{4}$

$$
\begin{gathered}
\lim _{N \rightarrow \infty}\left\{\frac{-\left(\frac{N+2}{N} w_{i}^{*}-A\right)}{-\frac{A}{t}+\frac{N+2}{N t} w_{i}^{*}-\frac{1}{N^{2}}}\left(A-w_{i}^{*}-1\right)-\frac{t}{4}\right\}<0 \\
\frac{A}{-\frac{A}{t}}(A-1)+\frac{t}{4}<0 \\
A>\frac{5}{4}
\end{gathered}
$$




\section{References}

Anderson, S.P. [2005], "The Regulation of Television Advertising", mimeo.

Anderson, S.P. And S. Coate [2005], "Market Provision of Public Goods: The Case of Broadcasting", Review of Economic Studies, 72, 947-972.

Armstrong, M. [2006], "Competition in Two-Sided Markets", Rand Journal of Economics, forthcoming.

Campell, A. J. [1999], "Self-Regulation and the Media" Federal Communications Law Journal, 51, 712 - 775.

Caulllad, B. And B. Jullien [2003]," Chicken and Egg: Competition among Intermediation Service Providers", Rand Journal of Economics, 34(2), 309328.

Chor, J. P. [2003], "Broadcast Competition and Advertising with Free Entry", mimeo.

Crampes, C. C. Haritchabalet and B. Jullien [2004], "Competing with Advertising Resources", mimeo.

Cunnigham, B.M. And P.J. Alexander [2004], "A Theory of Broadcast Media Concentration and Commercial Advertising", Journal of Public Economic Thoery, 6(4) 557-575.

Häckner, J. And S. Nyberg [2000], "Price Competition, Advertising and Media Market Concentration", mimeo.

Gal-Or, E. ANd A. Dukes [2003], "Minimal Differentiation in Commercial Media Markets", Journal of Economics and Management Strategie, 12, 291335 .

Gal-Or, E. And A. Dukes [2006], "On the Profitability of Media Mergers", Journal of Business, forthcoming.

Gabszewicz Jean J., Didier Laussel and Nathalie Sonnac [2004], "Programming and Advertising Competition in the Broadcasting Industry", Journal of Economics and Management Strategy, 13(4), 657-669. 
Goettler, R. [1998], "Advertising Rates, Audience Composition, and Competition in the Network Television Industry", GISA Working Paper, No. 1999-E28.

Kind, H.J. T. Nilssen and L. Sorgard [2005], "Advertising on TV: Underor Overprovision", mimeo.

Kohlschein, I. [2004], "Economic Distortions caused by Public Funding of Broadcasting in Europe", mimeo.

Nilssen T. And L. Sorgard [2001], "The TV Industry: Advertising and Programming", University of Oslo WP, No. 18/2001.

Nocke, V. and M. Peitz and K. Stahl [2004], "Platform Ownership", mimeo.

Reisinger, M. [2004], "Two-Sided Markets with Negative Externalities", mimeo.

Peitz, M. And T. Valetti [2004], "Content and Advertising in the Media: Pay-TV versus Free-To-Air", CEPR Working Paper, No. 4771.

Rochet, J.-C. And J. Tirole [2003], "Platform Competition in Two-Sided Markets", Journal of the European Economic Association, 1(4), 990 - 1029.

Rochet, J.-C. And J. Tirole [2004], "Two-Sided Markets: An Overview", IDEI Working Paper, No. 275. 